\title{
Aerosol composition, oxidation properties, and sources in Beijing: results from the 2014 Asia-Pacific Economic Cooperation summit study
}

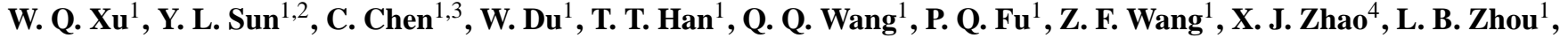 \\ D. S. Ji ${ }^{1}$, P. C. Wang ${ }^{5}$, and D. R. Worsnop ${ }^{6}$ \\ ${ }^{1}$ State Key Laboratory of Atmospheric Boundary Layer Physics and Atmospheric Chemistry, Institute of Atmospheric \\ Physics, Chinese Academy of Sciences, Beijing, China \\ ${ }^{2}$ Collaborative Innovation Center on Forecast and Evaluation of Meteorological Disasters, Nanjing University of Information \\ Science \& Technology, Nanjing, China \\ ${ }^{3}$ College of Applied Meteorology, Nanjing University of Information Science and Technology, Nanjing, China \\ ${ }^{4}$ Institute of Urban Meteorology, China Meteorological Administration, Beijing, China \\ ${ }^{5}$ Key Laboratory of Middle Atmosphere and Global Environment Observation, Institute of Atmospheric Physics, Chinese \\ Academy of Sciences, Beijing, China \\ ${ }^{6}$ Aerodyne Research, Inc., Billerica, Massachusetts, USA
}

Correspondence to: Y. L. Sun (sunyele@mail.iap.ac.cn)

Received: 13 July 2015 - Published in Atmos. Chem. Phys. Discuss.: 31 August 2015

Revised: 11 November 2015 - Accepted: 29 November 2015 - Published: 10 December 2015

\begin{abstract}
The mitigation of air pollution in megacities remains a great challenge because of the complex sources and formation mechanisms of aerosol particles. The 2014 Asia-Pacific Economic Cooperation (APEC) summit in Beijing serves as a unique experiment to study the impacts of emission controls on aerosol composition, size distributions, and oxidation properties. Herein, a high-resolution time-of-flight aerosol mass spectrometer was deployed in urban Beijing for real-time measurements of size-resolved non-refractory submicron aerosol $\left(\mathrm{NR}-\mathrm{PM}_{1}\right)$ species from 14 October to 12 November 2014, along with a range of collocated measurements. The average $( \pm \sigma) \mathrm{PM}_{1}$ was 41.6 $( \pm 38.9) \mathrm{\mu g} \mathrm{m}^{-3}$ during APEC, which was decreased by $53 \%$ compared with that before APEC. The aerosol composition showed substantial changes owing to emission controls during APEC. Secondary inorganic aerosol (SIA: sulfate + nitrate + ammonium) showed significant reductions of $62-69 \%$, whereas organics presented much smaller decreases $(35 \%)$. The results from the positive matrix factorization of organic aerosol (OA) indicated that highly oxidized secondary organic aerosol (SOA) showed decreases similar to those of SIA during APEC. However, primary organic
\end{abstract}

aerosol (POA) from cooking, traffic, and biomass-burning sources were comparable to those before APEC, indicating the presence of strong local source emissions. The oxidation properties showed corresponding changes in response to OA composition. The average oxygen-to-carbon level during APEC was $0.36( \pm 0.10)$, which is lower than the 0.43 $( \pm 0.13)$ measured before APEC, demonstrating a decrease in the OA oxidation degree. The changes in size distributions of primary and secondary species varied during APEC. SIA and SOA showed significant reductions in large accumulation modes with peak diameters shifting from $\sim 650$ to $400 \mathrm{~nm}$ during APEC, whereas those of POA remained relatively unchanged. The changes in aerosol composition, size distributions, and oxidation degrees during the aging processes were further illustrated in a case study of a severe haze episode. Our results elucidated a complex response of aerosol chemistry to emission controls, which has significant implications that emission controls over regional scales can substantially reduce secondary particulates. However, stricter emission controls for local source emissions are needed for further mitigating air pollution in the megacity of Beijing. 


\section{Introduction}

Atmospheric aerosols, especially fine particles of particulate matter (PM) with aerodynamic diameters less than $2.5 \mu \mathrm{m}$, play significant roles in human health hazards (Pope et al., 2009) and visibility reduction (Chow et al., 2002). Atmospheric aerosols also exert highly uncertain effects on climate change (Forster et al., 2007). Recently, the severe haze pollution, which is characterized by high concentrations of fine particles, has become a significant concern in China (Zhang et al., 2010). Consequently, extensive studies have been conducted to investigate the sources, formation mechanisms, and evolution processes of haze pollution during the last decade. The results showed that fine particles were mainly composed of organic matter (OM) and secondary inorganic aerosol (SIA) including sulfate, nitrate, and ammonium. The major sources of $\mathrm{PM}_{2.5}$ were also identified and quantified by using receptor models, e.g., factor analysis, chemical mass balance, positive matrix factorization (PMF) (Zheng et al., 2005; Song et al., 2006; Wang et al., 2008; Zhang et al., 2013), and tracer-based methods (Dan et al., 2004; Cao et al., 2005; Guo et al., 2012). Overall, traffic exhaust, industrial emissions, coal combustion, biomass burning, and secondary aerosols were the major sources of $\mathrm{PM}_{2.5}$. Cooking aerosol (COA) was also found to be a significant contributor of $\mathrm{PM}_{2.5}$ in urban environments (Huang et al., 2010b; Sun et al., 2010, 2013). Recent studies further highlighted the important roles of SIA and secondary organic aerosols (SOA) in the formation of severe haze pollution (Sun et al., 2014; Huang et al., 2014; Jiang et al., 2015; Zheng et al., 2015). The substantial emissions from primary sources and rapid secondary aerosol formation coupled with stagnant meteorological conditions lead to frequent haze pollution in China, particularly during winter (Sun et al., 2014). However, most previous studies are based on filter measurements with a time resolution ranging from hours to days, and our knowledge of the rapid formation of severe haze remains limited. Although recent real-time measurements of aerosol composition have improved our understanding of the evolutionary processes of haze pollution, most of them focus on chemical composition and source analysis, and the oxidation properties of aerosol particles remain less understood.

The aerodyne aerosol mass spectrometer (AMS) is unique for real-time characterization of size-resolved non-refractory submicron aerosol (NR-PM 1 ) composition (Jayne et al., 2000). The first deployments of quadrupole AMS (Q-AMS) at urban (Sun et al., 2010) and rural sites (Yufa) (Takegawa et al., 2009) in Beijing in 2006 showed significant differences in aerosol chemical compositions between the two sites. Organics dominated NR-PM 1 at both sites (33-35\%), whereas nitrate presented a much higher contribution at the urban site $(22 \%)$ than at the rural site $(11 \%)$. Three types of organic aerosol (OA) were identified: a hydrocarbon-like aerosol (HOA) from the primary emissions and two oxygenated organic aerosol (OOA) from the secondary forma- tion (Sun et al., 2010). The results highlighted the importance of SOA in summer, which on an average contributed $61 \%$ of the total OA. The high-resolution time-of-flight AMS (HRAMS), which provides more detailed chemical information and oxidation properties of OA, was first deployed in Beijing during the 2008 Olympic Games (Huang et al., 2010b). COA was first resolved by using AMS in Beijing and was observed to contribute a large fraction $(25 \%)$ of the total OA. The elemental composition of OA factors was also determined. The oxygen-to-carbon $(\mathrm{O} / \mathrm{C})$ ratios of SOA $(0.47-0.48)$ were significantly higher than those of primary OA (0.11-0.17), indicating significant differences in the oxidation degrees of primary and secondary aerosols. Since 2008, the HR-AMS has been deployed in various environments, mainly in Beijing (J. K. Zhang et al., 2014; Zhang et al., 2015; Sun et al., 2015a), the Yangtze River Delta (YRD) (Huang et al., 2013), the Pearl River Delta (PRD) (He et al., 2011; Huang et al., 2011), and Lanzhou in northwest China (Xu et al., 2014). The average mass concentrations of submicron aerosol $\left(\mathrm{PM}_{1}\right)$ in China ranged from 15 to $67 \mu \mathrm{g} \mathrm{m}^{-3}$ with organics constituting the major fraction $(28-52 \%)$. The OA factors identified by PMF analysis include HOA, COA, biomass-burning (BBOA), coal combustion (CCOA), semi-volatile OOA (SV-OOA), and lowvolatility OOA (LV-OOA). The OA factors varied substantially with seasons and sampling site environments.

Despite these results, few HR-AMS measurements have been reported in Beijing. Although the recent deployments of an aerosol chemical speciation monitor (ACSM) have illustrated the chemical evolution of aerosol species and OA factors in various seasons (Sun et al., 2012a, 2013, 2015b), our understanding of the evolution of size distributions and elemental composition of OA in Beijing is still limited. J. K. Zhang et al. (2014) reported a detailed characterization of submicron aerosol composition, OA composition, and elemental composition of OA in January 2013. The results highlighted the vast differences in aerosol chemistry between clean and polluted days. Zhang et al. (2015) further analyzed two HR-AMS data sets collected in August and October in Beijing. The results showed higher oxidation degree of OA in summer than that in fall, in addition to differences in OA compositions during the two seasons.

Compared with previous HR-AMS measurements in Beijing, this study was conducted at a unique time during the Asia-Pacific Economic Cooperation (APEC) summit. To ensure good air quality during APEC, strict emission controls were implemented in Beijing and in the surrounding regions, which included restrictions on the number of vehicles in operation, factory operations, construction activities, and open barbeques. This study provides a unique opportunity to study the impacts of source emissions on aerosol chemistry in a megacity such as Beijing. Similar emission controls, including temporary closures of factories and restrictions on traffic, were implemented to a lesser degree during the 2008 Olympic Games (Cermak and Knutti, 2009). Numerous stud- 
ies have investigated the impacts of emission controls on reductions in PM levels and secondary aerosol precursors during the Olympic Games. Emission controls were shown to significantly reduce primary aerosols and traffic-related gaseous and volatile organic compounds (Wang et al., 2010; Wang et al. 2011; Shao et al., 2011; Guo et al., 2013), although the impacts on secondary species were significantly lower (Wang et al., 2010; Guo et al., 2013). In addition, meteorological conditions were shown to play a more important role than emission controls in reducing PM levels during the Olympic Games (Wang et al., 2009; Cermak and Knutti, 2009). Therefore, significant uncertainties remain despite investigations of the response of aerosol chemistry to emission controls, and the link between emission controls and sources and the chemical composition of aerosol particles is far from being clearly understood.

In this study, we conduct real-time measurements of sizeresolved NR-PM 1 composition by using an HR-AMS along with a suite of collocated instruments from 14 October to 12 November 2014. The submicron aerosol composition, diurnal variations, size distributions, elemental composition, and sources of OA are investigated in detail. In particular, the impacts of emission controls and meteorological variables on aerosol composition, size distributions, and oxidation properties are elucidated by comparing the aerosol chemistry before and during APEC. In addition, a comprehensive analysis is performed to illustrate the chemical evolution of aerosol properties during a severe haze pollution event.

\section{Experimental methods}

\subsection{Sampling and instrumentation}

\subsubsection{Sampling}

This study took place from 14 October to 12 November 2014, at the Institute of Atmospheric Physics, Chinese Academy of Sciences, between the north 3rd and 4th ring roads in Beijing. The HR-AMS was stored in a trailer near ground level with a sampling height of approximately $4 \mathrm{~m}$. Aerosol particles were sampled into the trailer at a flow rate of $10 \mathrm{~L} \mathrm{~min}^{-1}$, of which $\sim 0.1 \mathrm{~L} \mathrm{~min}^{-1}$ was isokinetically sampled into the HR-AMS. A PM 2.5 cyclone (model URG-2000-30EN) was mounted in front of the sampling line to remove coarse particles larger than $2.5 \mu \mathrm{m}$. In addition, aerosol particles were dried by a diffusion silica-gel dryer before sampling into the HR-AMS. The collocated measurements in the trailer included particle extinction $(630 \mathrm{~nm})$ of $\mathrm{PM}_{2.5}$ by a cavity attenuated phase shift extinction monitor (CAPS PMext, Aerodyne Research Inc.), gaseous $\mathrm{NO}_{2}$ by a CAPS- $\mathrm{NO}_{2}$ monitor, and black carbon (BC) by a two-wavelength Aethalometer (model AE22, Magee Scientific Corp.). In addition, gaseous species (such as $\mathrm{CO}, \mathrm{O}_{3}, \mathrm{NO}, \mathrm{NO}_{y}$, and $\mathrm{SO}_{2}$ ) were simultaneously measured at a nearby two-story building by us- ing a series of gas analyzers from Thermo Scientific. Meteorological parameters such as relative humidity (RH), temperature, wind speed (WS), and wind direction (WD) were obtained at 15 heights from the Beijing $325 \mathrm{~m}$ meteorological tower, which is approximately $30 \mathrm{~m}$ from the sampling site. The wind profiles, including WS and WD between 100 and $5000 \mathrm{~m}$, were measured by a Doppler wind lidar (Windcube 200, Leosphere, Orsay, France) at the same location. All of the data in this study are reported in Beijing Standard Time (BST), which is equivalent to Coordinated Universal Time (UTC) plus $8 \mathrm{~h}$.

\subsubsection{HR-AMS operations}

The HR-AMS was operated by alternating the mass-sensitive $\mathrm{V}$-mode and the high-mass-resolution W-mode every $5 \mathrm{~min}$. Under V-mode operation, the HR-AMS cycled through the mass spectrum (MS) and particle time-of-flight (PToF) modes every $10 \mathrm{~s}$. No PToF data were collected in the Wmode due to the limited signal-to-noise $(S / N)$ ratio. The particle-free ambient air was sampled and analyzed to determine the detection limits (DLs) of NR-PM $M_{1}$ species and the fragment ion ratios of gases for subsequent high-resolution analysis. The 5 min DLs of organics, sulfate, nitrate, ammonium, and chloride of $\mathrm{V}$ - and $\mathrm{W}$-modes determined as 3 times the standard deviations $(3 \sigma)$ were $0.017,0.010,0.0016$, 0.0014 , and $0.004 \mu \mathrm{g} \mathrm{m}^{-3}$ and $0.030,0.035,0.026,0.0049$, and $0.032 \mu \mathrm{g} \mathrm{m}^{-3}$, respectively. Prior to this study, the ionization efficiency (IE) and particle sizes were calibrated using pure ammonium nitrate particles and polystyrene latex spheres (PSL; density: $1.05 \mathrm{~g} \mathrm{~cm}^{-3}$ ), respectively, following previous standard protocols (Jayne et al., 2000; Jimenez, 2003; Drewnick et al., 2005).

\subsection{HR-AMS data analysis}

The mass concentrations and size distributions of NR-PM were analyzed by using standard AMS data analysis software (SQUIRREL v1.56 and PIKA v 1.15D) written in Igor Pro 6.12A (Wavemetrics, Lake Oswego, OR, USA). A constant collection efficiency (CE) of 0.5 was applied for the quantification of NR-PM $\mathrm{N}_{1}$ species because aerosol particles were dry and were slightly acidic as indicated by

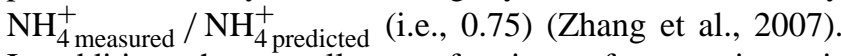
In addition, the overall mass fractions of ammonium nitrate were below the threshold value $(40 \%)$ that significantly affects the CE (Matthew et al., 2008). Therefore, the three major factors, humidity, particle acidity, and ammonium nitrate fraction, did not significantly affect the universal $\mathrm{CE}=0.5$, which has been widely used in numerous AMS studies. However, a constant $\mathrm{CE}$ value may introduce an uncertainty of 20-30\% for the mass concentrations of NR-PM 1 species (Middlebrook et al., 2012). The default relative ionization efficiencies of 1.4 for organics, 1.2 for sulfate, 1.1 for nitrate, and 1.3 for chloride were used (Allan 


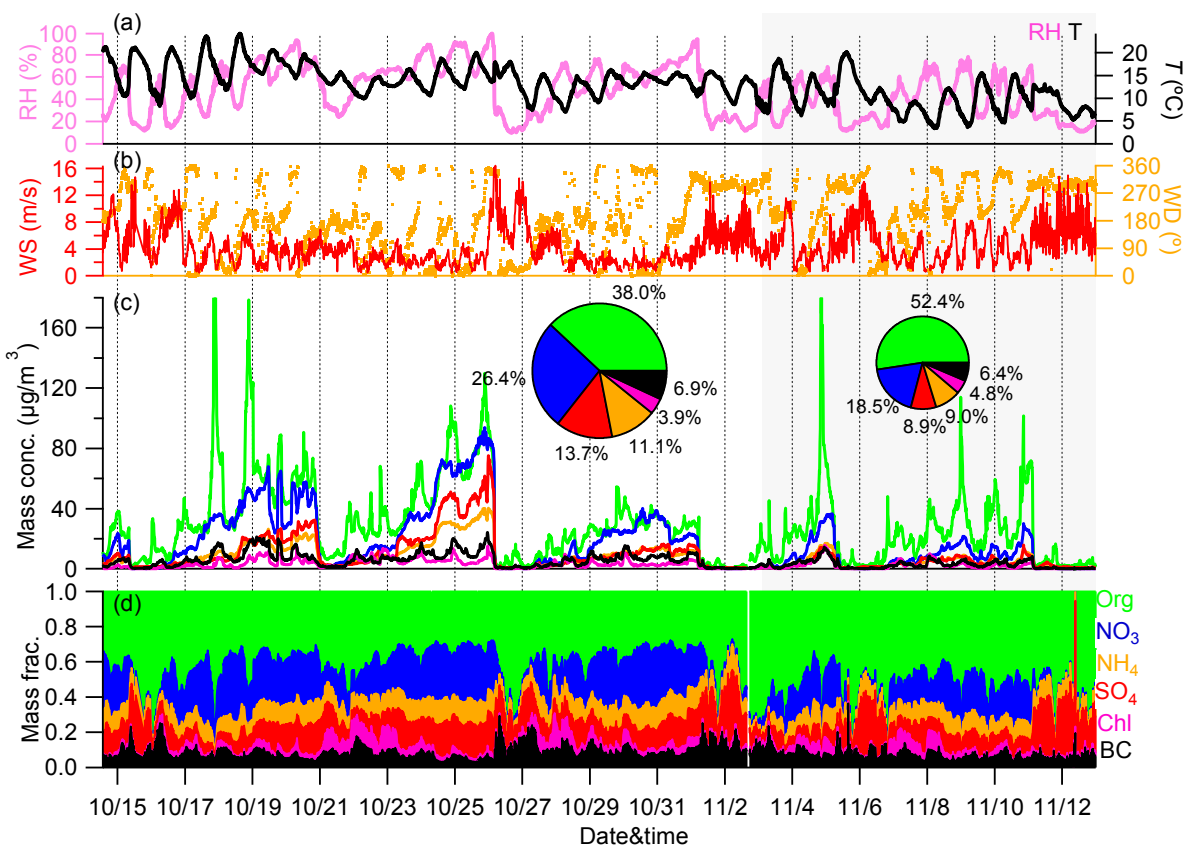

Figure 1. Time series of (a) relative humidity (RH), temperature ( $T)$, (b) wind direction (WD), wind speed (WS), (c) mass concentrations, and (d) mass fractions of chemical species in $\mathrm{PM}_{1}$. The pie charts show the average chemical composition of $\mathrm{PM}_{1}$ measured before and during the Asia-Pacific Economic Cooperation (APEC) summit.

et al., 2003) in this study; that for ammonium, 5.0, was determined from pure $\mathrm{NH}_{4} \mathrm{NO}_{3}$ particles. The total $\mathrm{PM}_{1}$ mass (i.e., $\left.\mathrm{NR}-\mathrm{PM}_{1}+\mathrm{BC}\right)$ agreed well with $\mathrm{PM}_{2.5}\left(R^{2}=0.86\right)$. The average ratio of $\mathrm{PM}_{1} / \mathrm{PM}_{2.5}, 0.77$, was also consistent with that reported in previous studies (Sun et al., 2014). This result further supports that $\mathrm{CE}=0.5$ is reasonable for this study.

The high-resolution mass spectra (HRMS) of the V-and $\mathrm{W}$-modes were analyzed for ion-speciated fragments of $\mathrm{C}_{x} \mathrm{H}_{y}^{+}, \mathrm{C}_{x} \mathrm{H}_{y} \mathrm{O}_{z}^{+}, \mathrm{C}_{x} \mathrm{H}_{y} \mathrm{~N}_{p}^{+}$, and $\mathrm{C}_{x} \mathrm{H}_{y} \mathrm{O}_{z} \mathrm{~N}_{p}^{+}$using PIKA $\mathrm{v} 1.15 \mathrm{D}$. The elemental composition of $\mathrm{OA}$, including ratios of oxygen-to-carbon $(\mathrm{O} / \mathrm{C})$, hydrogen-to-carbon $(\mathrm{H} / \mathrm{C})$, organic mass to organic carbon (OM / OC), and nitrogen-tocarbon $(\mathrm{N} / \mathrm{C})$, was determined by using the elemental analysis approach recommended by Aiken et al. (2007), referred to here as Aiken ambient (A-A). We also calculated the elemental ratios using the improved calibration factors recommended by Canagaratna et al. (2015), referred to here as improved ambient (I-A). The average $\mathrm{A}-\mathrm{A} \mathrm{H} / \mathrm{C}$ and $\mathrm{O} / \mathrm{C}$ ratios were 1.55 and 0.41 , which are respectively 8 and $20 \%$ lower than the I-A H / C and O / C ratios of 1.69 and 0.51 . For consistency with previous studies, the elemental composition determined from the A-A approach was reported in this study. The PMF2.exe algorithm (v4.2) in robust mode (Paatero and Tapper, 1994) was applied to the HRMS matrix $(4158 \times 306)$ of $\mathrm{OA}$ for the entire study period to resolve distinct OA factors representing specific sources and processes. Values of $\mathrm{m} / \mathrm{z}$ larger than 120 were excluded due to the limited mass resolution in separating higher mass ions.
Isotopic ions scaled on the basis of the signals of parent ions were also excluded. Such exclusion had a minor impact on the total mass $(\sim 2-3 \%)$. Other data pretreatments were similar to those reported in previous studies; that is, the bad ions with $S / N<0.2$ were removed, and the weak ions with $0.2<S / N<3$ were further down-weighted by increasing their errors by a factor of 3 .

The PMF solutions were investigated in detail by evaluating the mass spectral profiles and time series of OA factors ( 1 to 10$)$ as a function of rotational parameter $\left(f_{\text {Peak }}\right)$. By comparing the mass spectral profiles of OA factors with previously reported standard mass spectra, and the time series with external tracers, such as $\mathrm{CO}, \mathrm{NO}_{x}, \mathrm{BC}$, SIA, $\mathrm{C}_{3} \mathrm{H}_{5} \mathrm{O}^{+}$, and $\mathrm{C}_{2} \mathrm{H}_{3} \mathrm{O}^{+}$, a six-factor solution with $f_{\text {Peak }}=0$ was selected in this work. The five-factor solution yielded a mixed SOA factor and the seven-factor solution split the SV-OOA into two components, which cannot be reasonably explained due to limited external tracers. A summary of the key diagnostic plots of the PMF results is shown in Figs. S1-S3 in the Supplement.

\section{Results and discussion}

\subsection{Mass concentrations and chemical composition}

Figure 1 shows the time series of submicron aerosol species during the entire study period. All aerosol species varied dramatically between haze episodes and clean periods. As indi- 
Table 1. Summary of average meteorological parameters, mass concentrations of $\mathrm{PM}_{1}$ species and OA factors for the entire study, before and during APEC, and also the change percentages during APEC.

\begin{tabular}{lrrrr}
\hline & Entire study & Before APEC & APEC & Change perc. $(\%)$ \\
\hline Meteorological parameters & & & & \\
\hline $\mathrm{RH}(\%)$ & 47.5 & 52.8 & 37.4 & \\
$T\left({ }^{\circ} \mathrm{C}\right)$ & 13.0 & 14.5 & 10.1 & \\
\hline $\mathrm{PM}_{1}$ species $\left(\mu \mathrm{g} \mathrm{m}^{-3}\right)$ & & & \\
\hline $\mathrm{Org}_{\mathrm{SO}}$ & & & & \\
$\mathrm{NO}_{3}$ & 29.4 & 33.6 & 21.8 & 35.1 \\
$\mathrm{NH}_{4}$ & 9.1 & 12.0 & 3.7 & 69.2 \\
$\mathrm{Ch}$ & 17.8 & 23.1 & 7.7 & 66.7 \\
$\mathrm{BC}$ & 7.8 & 9.8 & 3.7 & 62.2 \\
$\mathrm{PM}_{1}$ & 2.9 & 3.4 & 2.0 & 41.2 \\
\hline $\mathrm{OA}\left(\mu \mathrm{g} \mathrm{m}{ }^{-3}\right)$ & 4.8 & 6.1 & 2.7 & 55.7 \\
\hline $\mathrm{COA} 1$ & 71.8 & 88.0 & 41.6 & 52.7 \\
$\mathrm{COA} 2$ & & & & \\
$\mathrm{HOA}$ & & & & \\
$\mathrm{BBOA}$ & 5.5 & 5.9 & 4.7 & 20.3 \\
$\mathrm{SV}-\mathrm{OOA}$ & 2.0 & 2.2 & 1.6 & 27.3 \\
$\mathrm{LV}_{-} \mathrm{OOA}$ & 3.4 & 3.6 & 2.9 & 19.4 \\
\hline
\end{tabular}

cated in the figure, three evident pollution episodes before APEC and two episodes during APEC were observed. The formation and evolution of the haze episodes were closely related to stagnant meteorology characterized by low WS and high RH. The average $( \pm \sigma)$ mass concentration of $\mathrm{PM}_{1}$ was $41.6( \pm 38.9) \mu \mathrm{g} \mathrm{m}^{-3}$ during APEC, which was $52.7 \%$ lower than the $88.0 \mu \mathrm{g} \mathrm{m}^{-3}$ measured before APEC. Periods of high $\mathrm{PM}_{1}$ concentration $\left(>60 \mu \mathrm{g} \mathrm{m}^{-3}\right.$ ) accounted for $56.7 \%$ of the time before APEC and $22.6 \%$ during APEC. These results indicate significant reductions in PM during APEC, particularly for pollution events with high $\mathrm{PM}_{1}$ loading.

The variations of inorganic aerosol and organics showed different behaviors before and during APEC. Figure 1c shows clear decreases in inorganic aerosol species on 3 November, when emission controls were first implemented in Beijing. Relatively low ambient levels were maintained on 6 November, when far stricter emission controls were imposed in Beijing and in the surrounding regions. As a comparison, the variations in organics were more dramatic, and the changes during APEC were not as significant as those for inorganic aerosol species. Although SIA, such as sulfate, nitrate, and ammonium, were decreased by $62-69 \%$ during APEC, organics showed a much smaller decrease of $35 \%$ (Table 1). The chemical composition of $\mathrm{PM}_{1}$ before APEC was mainly composed of organics, accounting for $38.0 \%$, followed by nitrate at $26.4 \%$ and sulfate at $13.7 \%$. The average aerosol composition during APEC showed significant changes. The contribution of organics showed a large increase, accounting for more than half of $\mathrm{PM}_{1}$, whereas that of SIA was decreased from 51.2 to $35.4 \%$. These results suggest different responses of SIA and OA to emission controls. However, the measurements at $260 \mathrm{~m}$ at the same location showed significant decreases of $40-80 \%$ for all aerosol species during APEC, whereas the bulk aerosol composition was relatively similar before and during APEC as a result of synergetic controls of aerosol precursors over a regional scale (Chen et al., 2015). These results indicated the different sources of aerosol particles between the ground site and $260 \mathrm{~m}$. Compared with previous AMS studies in Beijing, we observed a significantly higher nitrate contribution before APEC in summer 2008 (15.8\%) (Huang et al., 2010b) and in winter 2011-2012 (16.0\%) (Sun et al., 2013). The average mass ratio of $\mathrm{NO}_{3} / \mathrm{SO}_{4}$ was 1.78 , which is also significantly higher than the values $(0.78-1.04)$ previously reported in China (Y. Zhang et al., 2012; Y. M. Zhang et al., 2014). A high nitrate contribution to $\mathrm{PM}_{1}$ was also observed at $260 \mathrm{~m}$, which accounted for 27 and $29 \%$, respectively, before and during APEC (Chen et al., 2015). Thus, our results elucidate the important role of nitrate in PM pollution during the study period.

\subsection{Diurnal cycles}

The diurnal cycles of $\mathrm{PM}_{1}$ species before and during APEC are illustrated in Fig. 2. SIA showed similar pronounced diurnal cycles before APEC, which were all characterized by gradual increases during daytime. Such diurnal cycles were primarily driven by photochemical processing, considering 


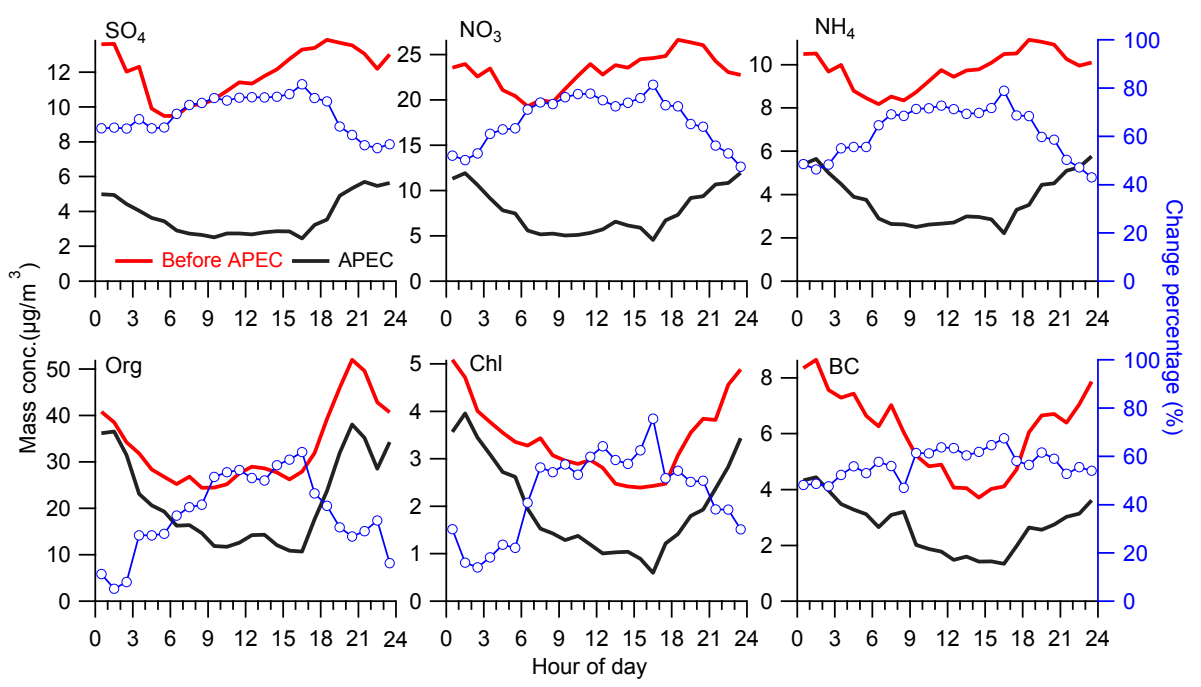

Figure 2. Diurnal profiles of the mass concentrations of $\mathrm{PM}_{1}$ species measured before and during the Asia-Pacific Economic Cooperation (APEC) summit. Also shown are the changes in percentage of aerosol species occurring during APEC.

the rising planetary boundary layer height during daytime. Similar diurnal cycles of SIA were also observed during winter in 2011-2012 (Sun et al., 2013). Note that the ratio of $\mathrm{NO}_{3} / \mathrm{SO}_{4}$ was not constant throughout the day. In fact, a gradual decrease in $\mathrm{NO}_{3} / \mathrm{SO}_{4}$ from $\sim 2.2$ to 1.9 was observed during daytime, indicating additional evaporative loss of nitrate particles because of gas-particle partitioning. The diurnal cycles of SIA during APEC differed significantly. The concentrations of SIA at night were nearly twice that during the day. A detailed check of the meteorology and time series of aerosol species during APEC revealed that the routine circulation of mountain-valley breeze played a dominant role in driving the diurnal variations. As indicated in Fig. 1, a northwesterly mountain-valley breeze occurred regularly at midnight on 9-10 November when the mass concentrations of aerosol species began to decrease. The mountain-valley breeze dissipated at approximately noon when the WD changed from the northwest to the south, and the mass concentrations reached the minimum daily level. Consequently, the change percentages of SIA (i.e., ([Before APEC]-[During APEC])/([Before APEC])) showed pronounced diurnal cycles with the greatest decrease during daytime. Because SIA was formed mainly over a regional scale and was less influenced by local sources, we can roughly estimate the relative contributions of emission controls and mountain-valley breeze effects. Assuming that the decreases in SIA during APEC were caused mainly by emission controls and the mountain-valley breeze, and that the decreases in SIA at night without the mountain-valley breeze were caused solely by emission controls, we can estimate that approximately $27 \%$ of reduction in sulfate and nitrate during the day was caused by the cleaning effects of the mountainvalley breeze.
Organics showed a substantially different diurnal cycle from that of SIA, characterized by a pronounced nighttime peak and a visible noon peak. The diurnal cycles of OA factors indicated that such diurnal variations were mainly driven by local primary sources such as cooking, traffic, and biomass-burning emissions. Although organics showed a decrease of approximately $60 \%$ during daytime, the differences before and during APEC were much smaller at nighttime, indicating that strong local sources emissions remained during APEC despite the strict emission controls. Chloride, mainly from combustion sources, e.g., biomass burning and coal combustion (Levin et al., 2010; H. Zhang et al., 2012), showed similar diurnal cycles before and during APEC with the greatest reduction occurring during daytime. Similarly, the small decrease in chloride at nighttime likely indicates the presence of a considerable amount of combustion emissions during APEC. The diurnal cycles of BC were similar before and during APEC, both characterized by significantly higher concentrations at nighttime that during the day. Such a diurnal cycle of $\mathrm{BC}$ is similar to that previously observed in Beijing (Han et al., 2009), indicating higher BC source emissions during nighttime. This result is consistent with the diurnal variations of diesel trucks and heavy-duty vehicles that are only allowed to operate inside the city between 22:00-06:00. Different from other aerosol species, the reduction in BC was relatively constant at $47.0-67.5 \%$ throughout the day, suggesting similar BC sources before and during APEC, but with different emission intensities. In addition, the mountain-valley breeze effect on $\mathrm{BC}$ was different from that on other species, likely due to the similar BC levels in northwest and south Beijing. 


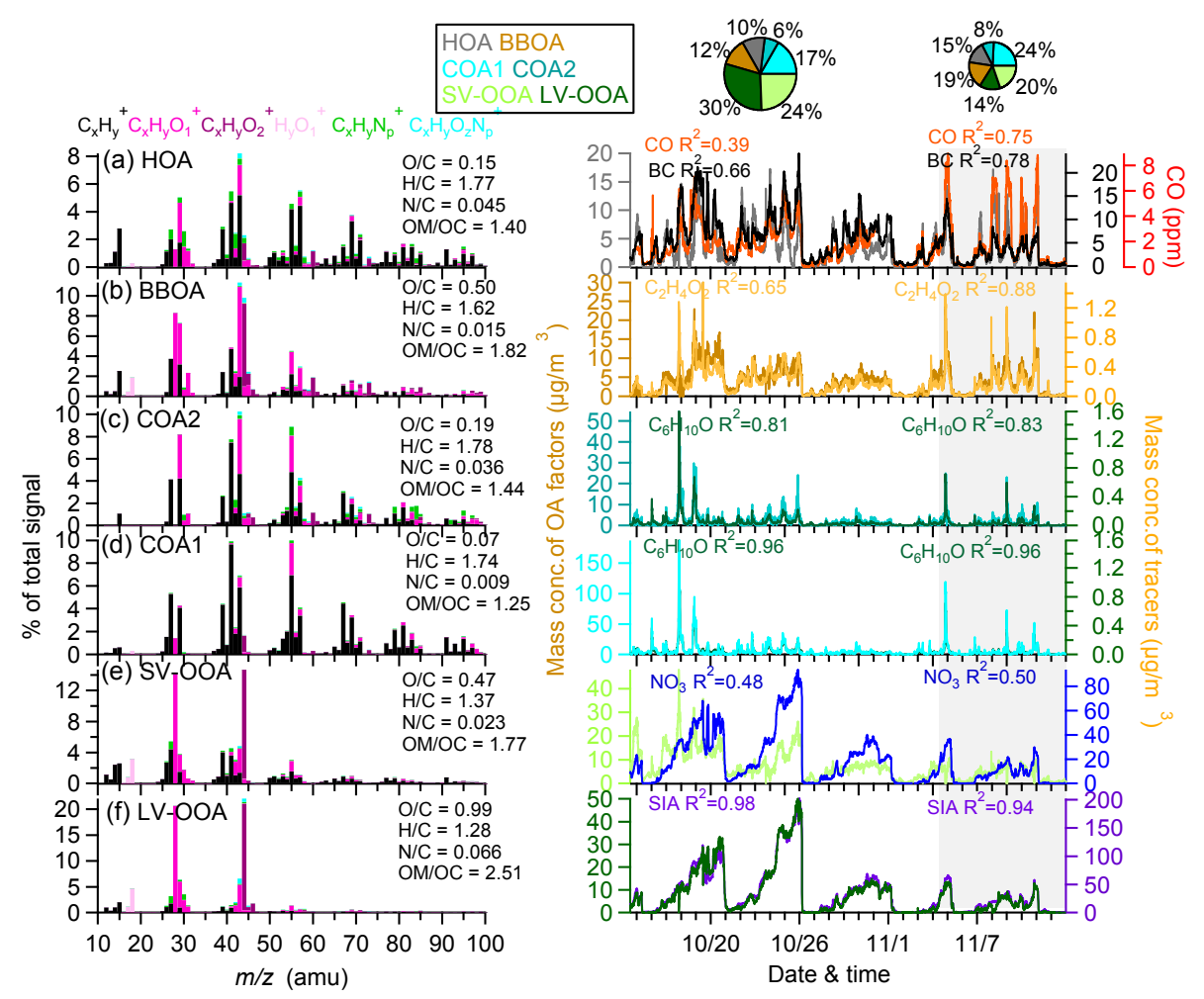

Figure 3. High-resolution mass spectra (HRMS; left panel) and time series (right panel) of six organic aerosol (OA) components: (a) hydrocarbon-like aerosol (HOA), (b) biomass-burning OA (BBOA), (c) cooking organic aerosol 2 (COA2), (d) COA1, (e) semi-volatile oxygenated OA (SV-OOA), and (f) low-volatility oxygenated OA (LV-OOA). Also shown in the right panel are the time series of tracers including $\mathrm{C}_{6} \mathrm{H}_{10} \mathrm{O}^{+}, \mathrm{C}_{2} \mathrm{H}_{4} \mathrm{O}_{2}^{+}, \mathrm{CO}$, black carbon (BC), nitrate, and SIA (sulfate + nitrate + ammonium). The two pie charts show the average chemical composition of $\mathrm{PM}_{1}$ measured before and during the Asia-Pacific Economic Cooperation (APEC) summit, respectively. The correlation coefficients between OA factors and external tracers measured before and during APEC are also shown in the figure.

\subsection{Composition and sources of $\mathrm{OA}$}

Six OA factors were identified by PMF analysis of HRMS of OA, including four primary OA factors (HOA, BBOA, COA1, and COA2), and two secondary OA factors (SV-OOA and LV-OOA). The mass spectra and time series of the six OA factors are shown in Fig. 3.

The HOA spectrum was characterized by prominent hydrocarbon ion series of $\mathrm{C}_{n} \mathrm{H}_{2 n+1}^{+}$and $\mathrm{C}_{n} \mathrm{H}_{2 n-1}^{+}$, which is consistent with that observed at various urban sites (Huang et al., 2010b; Sun et al., 2011; Xu et al., 2014). The O / C ratio of HOA was 0.17 , which is considerably higher than $0.03-$ 0.04 measured from diesel and gasoline exhausts (Mohr et al., 2009) and slightly higher than $0.11-0.13$ observed in the YRD (Huang et al., 2013), and the PRD in China (He et al., 2011), indicating that the HOA in this study was relatively oxidized. HOA correlated well with $\mathrm{BC}\left(R^{2}=0.78\right)$ during APEC, and the average HOA / BC ratio of 1.2 was consistent with that obtained in other megacities such as Mexico City (Aiken et al., 2009) and New York City (Sun et al., 2011). Although HOA also tightly correlated with BC before APEC $\left(R^{2}=0.66\right)$, a significantly lower ratio of $\mathrm{HOA} / \mathrm{BC}(0.57)$ was observed. These results suggest a substantial change of the sources of either HOA or BC during APEC. As shown in Fig. 2, BC showed large reductions similar to those of SIA during APEC, suggesting that a large fraction of BC was likely from regional transport. This result is consistent with a recent study at an urban site in Lanzhou (Xu et al., 2014) in which $53 \%$ of BC was found to be associated with SIA and SOA, and the rest (47\%) was from local primary emissions. Therefore, we infer that the HOA / BC ratio of 1.2 during APEC is likely representative of local source emissions, whereas lower HOA / BC ratios before APEC indicate additional $\mathrm{BC}$ sources such as regional transport. Therefore, the HOA / BC ratio can be used to indicate the relative importance between local emissions and regional transport. The increase in the $\mathrm{HOA} / \mathrm{BC}$ ratio during $\mathrm{APEC}$ illustrates a significant reduction of $\mathrm{BC}$ from regional transport owing to emission controls over a regional scale. Sun et al. (2014) also reported a large decrease in the $\mathrm{HOA} / \mathrm{BC}$ ratio during severe haze episodes in which approximately $53 \%$ of $\mathrm{BC}$ was from regional transport.

The HOA / CO ratios were similar before and during APEC, at 1.64 and 1.40 , respectively, but were significantly lower than the values reported in Mexico City (Aiken et al., 
2009) and Fresno, California (Ge et al., 2012b) at 5.71 and 5.64 , respectively. A likely explanation is that more complex sources of $\mathrm{CO}$ from traffic, cooking, and biomass burning were measured in this study. Indeed, HOA only correlated moderately with $\mathrm{CO}\left(R^{2}=0.39\right)$ before APEC. HOA showed similarly pronounced diurnal cycles before and during APEC with nighttime concentrations approximately 4-6 times that during the day (Fig. 5). The diurnal cycle of HOA resembled that of $\mathrm{BC}$, yet the reduction during APEC was significantly smaller, ranging from $\sim 20$ to $50 \%$ between 09:00 and 24:00. Note that the HOA concentration between 00:00 and 03:00 during APEC was even slightly higher than that before APEC, indicating the presence of emissions from diesel trucks and heavy-duty vehicles during this period. This result is consistent with the fact that vehicles use was limited only between 03:00 and 24:00 during APEC.

The mass spectra of the two COA factors were both characterized by high ratios of $m / z 55 / 57$, at 2.4 and 2.1, respectively, which is consistent with the spectral characteristics of fresh cooking aerosols (Mohr et al., 2009; He et al., 2010) and that of COA ubiquitously observed in megacities (Huang et al., 2010b; Sun et al., 2012b; Ge et al., 2012a). As shown in Fig. 3, the $\mathrm{O} / \mathrm{C}$ of $\mathrm{COA} 1$ was 0.07 , which is significantly lower than 0.19 of cooking organic aerosol 2 (COA2), suggesting significant differences in oxidation properties. Moreover, COA1 correlated more strongly with the tracer ion $\mathrm{C}_{6} \mathrm{H}_{10} \mathrm{O}^{+}$of $\mathrm{COA}$ (Sun et al., 2011) $\left(R^{2}=0.96\right)$ than COA2 $\left(R^{2}=0.81-0.83\right)$, which is indicative of their different sources. The diurnal cycles of COA 1 and COA2 were both characterized by pronounced evening peaks with maximum concentrations occurring between 20:00 and 21:00, indicating the large amount of cooking activities at nighttime. Note that the diurnal cycle of COA1 showed clear morning and noon peaks associated with breakfast and lunch emissions, which were almost invisible for COA2. Interestingly, a significant decrease in COA1 concentration was not observed during APEC, suggesting similar local cooking sources near the sampling site before and during APEC. However, COA2 showed a considerable reduction from late afternoon to midnight during APEC. This result suggests that the sources of COA2 were controlled to a certain degree during APEC. Considering that the major control of cooking emissions was the banning of open charcoal grills, we conclude that the COA2 was primarily from charbroiling emissions, whereas COA1 was more like a factor of regular cooking emissions.

The BBOA spectrum showed pronounced peaks at $m / z 60$, mainly $\mathrm{C}_{2} \mathrm{H}_{4} \mathrm{O}_{2}{ }^{+}$, and $m / z 73$, mainly $\mathrm{C}_{3} \mathrm{H}_{5} \mathrm{O}_{2}{ }^{+}$; these two maker ions indicate the presence of biomass burning (Alfarra et al., 2007; Aiken et al., 2009; Cubison et al., 2011). BBOA correlated strongly with $\mathrm{C}_{2} \mathrm{H}_{4} \mathrm{O}_{2}{ }^{+}$before and during APEC $\left(R^{2}=0.65\right.$ and 0.88 , respectively). The weaker correlation before APEC is likely due to other source contributions to $\mathrm{C}_{2} \mathrm{H}_{4} \mathrm{O}_{2}^{+}$such as cooking aerosol. The $\mathrm{O} / \mathrm{C}$ ratio of BBOA was 0.50 , which is significantly higher than that observed in Kaiping and Jiaxing in China at 0.26-0.27 (Huang
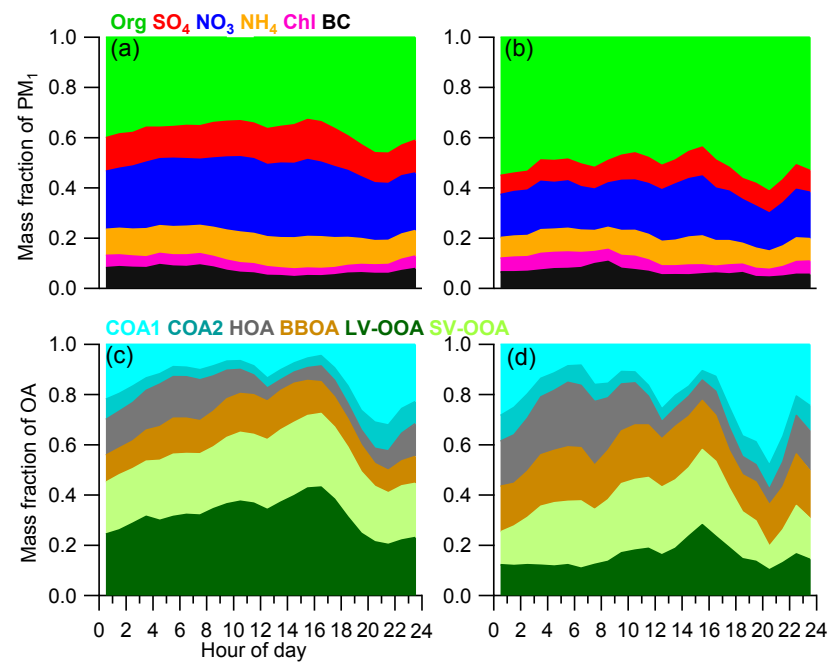

Figure 4. Diurnal evolution of the composition of $\mathrm{PM}_{1}$ and organic aerosol (OA) measured (a, c) before the Asia-Pacific Economic Cooperation summit (APEC) and (b, d) during APEC.

et al., 2011, 2013), and in Mexico City at 0.30 (Aiken et al., $2009)$; the $f 44$ of BBOA $(11.3 \%)$ was higher as well. Since biomass burning, e.g., agricultural burning in October, was rare inside the city of Beijing, the observed BBOA was expected to be mainly from regional transport. Previous studies have shown that BBOA can be rapidly oxidized in the atmosphere, leading to a decrease in $f 60$ and a corresponding increase in $f 44$ (Cubison et al., 2011). Therefore, we infer that BBOA in this study was an aged BBOA from regional transport. In fact, the $\mathrm{O} / \mathrm{C}$ ratio of $\mathrm{BBOA}$ was close to that of the aged BBOA observed from the aircraft measurements during the Megacity Initiative: Local and Global Research Observations (MILAGRO) project in 2006 (DeCarlo et al., 2010). The diurnal cycles of BBOA differed substantially before and during APEC. Although relatively flat before APEC, it presented a pronounced diurnal variation with nighttime concentration approximately 3 times that during daytime. Although the daytime BBOA concentration was reduced by $\sim 40 \%$ during APEC, the nighttime concentration was even higher than that before APEC. These results suggest that significant biomass-burning emissions remained in the surrounding regions of Beijing during APEC. The low daytime concentration was found to be mainly associated with the mountain-valley breeze that carried aerosols from the northwest with significantly lower biomass-burning emissions to Beijing.

Compared with primary organic aerosol (POA), the two OOA factors, SV-OOA and LV-OOA, showed significantly higher $f 44$ and $\mathrm{O} / \mathrm{C}$ ratios. The $f 44$ and $\mathrm{O} / \mathrm{C}$ of LV-OOA were 0.22 and 0.99 , respectively, indicating that LV-OOA was a highly aged SOA. Indeed, the $\mathrm{O} / \mathrm{C}$ of LV-OOA in this study was even higher than that previously observed at various urban sites in China, e.g., Shanghai, Lanzhou, Shen- 


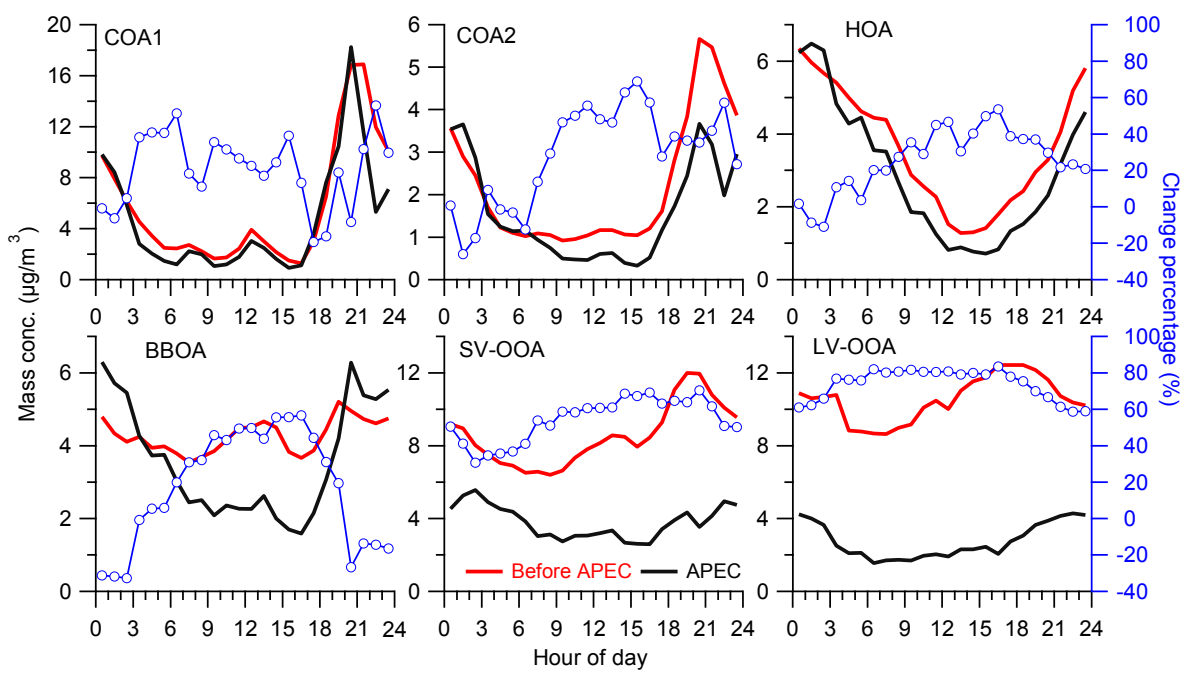

Figure 5. Diurnal profiles of the mass concentrations of organic aerosol (OA) factors measured before and during the Asia-Pacific Economic Cooperation (APEC) summit. Also shown are the changes in percentage of OA factors measured during APEC.

zhen, and Hong Kong at $\sim 0.6-0.8$ (He et al., 2011; Huang et al., 2012; Lee et al., 2013; Xu et al., 2014). LV-OOA highly correlated with SIA before and during $\operatorname{APEC}\left(R^{2}=0.98\right.$ and 0.94 , respectively), indicating the secondary nature of LVOOA. The diurnal cycle of LV-OOA before APEC showed a gradual increase during daytime, although the absolute increase at $\sim 4 \mu \mathrm{g} \mathrm{m}^{-3}$ was significantly smaller than the background concentration at $\sim 8 \mu \mathrm{g} \mathrm{m}^{-3}$. This result indicates that LV-OOA was mainly from regional transport, which is consistent with its high oxidation properties. Comparatively, LV-OOA showed a similar diurnal cycle as that of SIA during APEC characterized by a higher concentration at nighttime. As indicated in Fig. 4, LV-OOA showed the greatest reduction among OA factors, at $60-80 \%$, which indicates that regional emission controls exerted the most impact on LV-OOA. SV-OOA showed moderately high $f 44$ and $\mathrm{O} / \mathrm{C}$ at 0.15 and 0.47 , respectively, suggesting a lesser degree of photochemical processing. SV-OOA correlated with nitrate $\left(R^{2}=0.50\right)$, indicating similar semi-volatile properties (U1brich et al., 2009). However, significant differences in variation between SV-OOA and nitrate were also observed occasionally. In particular, the time series of SV-OOA showed sporadic peaks corresponding to those of COA, BBOA, and HOA, yet they were not observed in the nitrate time series. These results might suggest that part of freshly emitted OA can be rapidly oxidized to form SV-OOA. The diurnal cycle of SV-OOA before APEC showed an evident daytime increase, indicating photochemical processing. However, such a diurnal cycle was not observed during APEC. These results indicated that photochemical processing was not the major factor driving the diurnal variation of SV-OOA during APEC. In fact, we determined that the mountain-valley breeze played a more important role.
Overall, SOA dominated the OA composition before APEC with SV-OOA and LV-OOA accounting for 24.4 and $30.0 \%$, respectively. POA together accounted for $45.4 \%$ of the total OA with cooking aerosol being the largest component at $23 \%$. It should be noted that the COA contribution varied significantly throughout the day. Although COA showed a contribution of generally less than $20 \%$ during daytime, its contribution reached as high as $40 \%$ at dinner time (Fig. 4). BBOA also comprised a considerable fraction of $\mathrm{OA}$, at $12.2 \%$ on average. The average mass concentrations of SV-OOA and LV-OOA showed large decreases by 56 and $74 \%$, during APEC, respectively (Table 1), whereas those of primary OA showed significantly lower decreases ranging from 16 to $27 \%$. As a result, the bulk OA composition showed a substantial change during APEC. For example, the contribution of SOA decreased from $54 \%$ before APEC to $34 \%$ during APEC. Correspondingly, all primary OA factors showed elevated contributions to OA. As a comparison, POA at $260 \mathrm{~m}$ with much less influences from local sources showed a similar reduction to SOA (Chen et al., 2015). Our results have significant implications that controlling secondary precursors over regional scales can reduce secondary particulates substantially and hence mitigate air pollution in megacities. As previously discussed, the reduction of local primary emissions was significantly less than that of secondary aerosol during APEC; therefore, stricter control of local source emissions is crucial for improving air quality in the future.

The RH and wind dependence of SV-OOA and LV-OOA before and during APEC are shown in Fig. 6. Both SV-OOA and LV-OOA showed clear concentration gradients as a function of RH with higher concentrations associated with higher $\mathrm{RH}$ levels. The lowest concentrations of SV-OOA and LVOOA were observed at low RH levels $(<30 \%)$ with northerly 

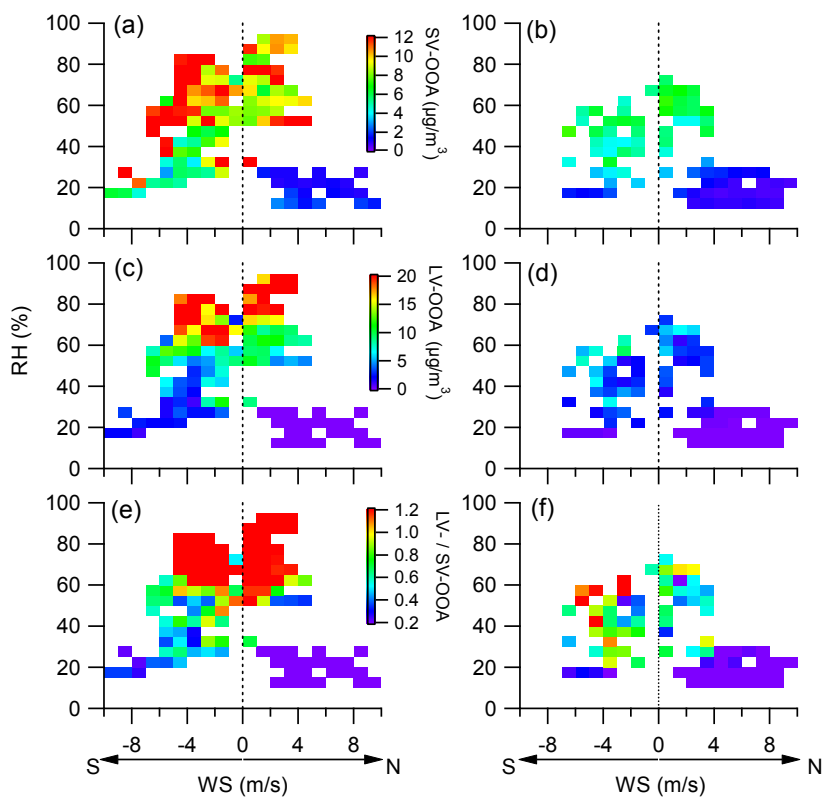

Figure 6. Relative humidity $(\mathrm{RH})$ and wind dependence (WD) of $(\mathbf{a}, \mathbf{b})$ semi-volatile oxygenated organic aerosols (SV-OOA), (c, d) low-volatility oxygenated organic aerosols (LV-OOA), and $(\mathbf{e}, \mathbf{f})$ the ratio of LV-OOA/SV-OOA measured before (left panel) and during the Asia-Pacific Economic Cooperation (APEC) summit (right panel). S refers to the south $\left(90^{\circ}<\mathrm{WD}<270^{\circ}\right)$, and $\mathrm{N}$ refers to the north $\left(0^{\circ}<\mathrm{WD}<90^{\circ}\right.$ and $\left.270^{\circ}<\mathrm{WD}<360^{\circ}\right)$. Grids with points numbering less than five were excluded.

winds. No significant differences in SOA, particularly LVOOA, were noted between the south and the north when the WS $(280 \mathrm{~m})$ was less than $4 \mathrm{~m} \mathrm{~s}^{-1}$ and the RH was above $60 \%$, indicating that SOA was relatively evenly distributed around the sampling site under stagnant meteorological conditions. The ratio of LV-OOA / SV-OOA was larger than 1 for most of the time at RH $>60 \%$, suggesting a more important role of highly oxidized SOA at high RH levels. In contrast, SV-OOA was more important than LV-OOA at low RH levels. SV-OOA and LV-OOA during APEC generally showed similar RH- and wind-dependent patterns (Fig. 6b, d). By comparing the SV-OOA and LV-OOA before and during APEC under similar RH and wind conditions, we can evaluate the impacts of emission controls on SOA. Both SV-OOA and LV-OOA showed significant reductions at RH $>40 \%$ suggesting that regional emission controls played a significant role in suppressing the formation of SOA. However, small changes and even increases of SV-OOA and LV-OOA in the low RH region from the north were observed, which is consistent with the fact that emission controls were implemented mainly in the regions south of Beijing. Figure $6 \mathrm{f}$ shows a very different ratio of LV-OOA / SV-OOA during APEC. In particular, SV-OOA was higher than LV-OOA for most of the time, indicating that SOA was less oxidized during APEC.

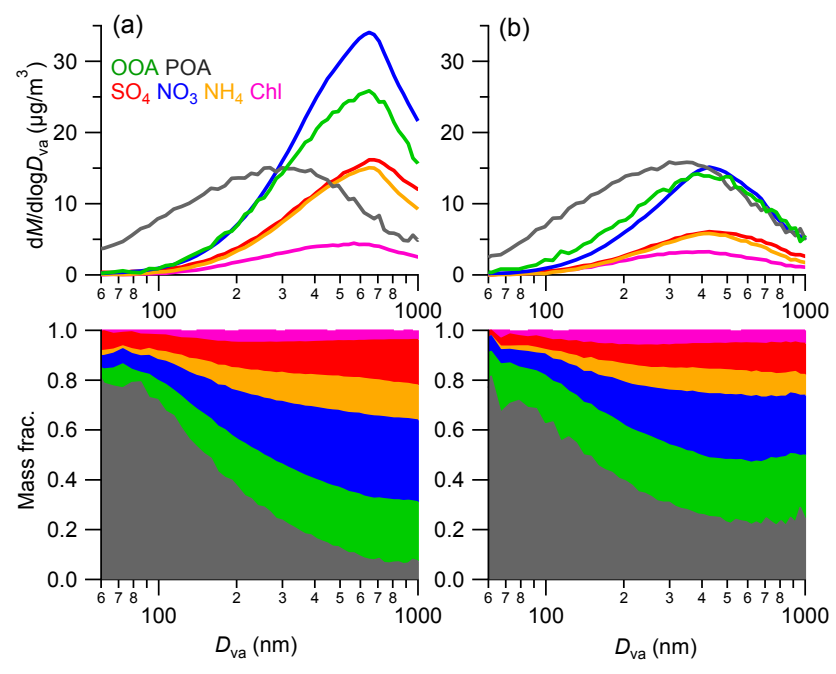

Figure 7. Average size distributions and fractions of NR-PM 1 species, primary organic aerosol (POA) and oxygenated organic aerosol (OOA) measured (a) before the Asia-Pacific Economic Cooperation (APEC) summit and (b) during APEC.

\subsection{Size distributions}

Figure 7 presents the average mass-weighted size distributions of NR-PM $M_{1}$ species before and during APEC. The size distributions of OOA were derived from that of $m / z 44$ by normalizing the integrated signals of $m / z 44$ between 30 and $1500 \mathrm{~nm}$ to the concentrations of OOA (Zhang et al., 2005). This method is rational because $m / z 44$ (mainly $\left.\mathrm{CO}_{2}\right)$ strongly correlated with OOA $\left(R^{2}=0.98\right)$. The size distributions of POA were then obtained from the differences between total OA and OOA. It should be noted that the OOA concentration might be slightly overestimated in small size ranges because $\sim 17 \%$ of $\mathrm{m} / z 44$ was constituted by POA. SIA and OOA showed similar single large accumulation modes peaking at $\sim 650 \mathrm{~nm}$ or even larger before APEC. In comparison, POA showed a much broader size distribution with the peak diameter occurring at $\sim 300 \mathrm{~nm}$. The size-resolved composition showed a dominant contribution of POA in small size ranges, accounting for almost $80 \%$ below $100 \mathrm{~nm}$, whereas the contributions of SIA and OOA increased significantly from $\sim 20 \%$ to more than $90 \%$ as the particle diameter increased from 100 to $1000 \mathrm{~nm}$. These results indicate the dominant contributions of secondary aerosol to accumulation-mode particles, whereas primary emissions played more significant roles in ultrafinemode particles. The differences in size distributions between POA and secondary aerosol also highlight their different sources and aging processes.

The size distributions of SIA and OOA showed substantial changes during APEC. Although the mass concentrations in the accumulation mode were reduced by approximately $50 \%$, the peak diameters also shifted to smaller sizes 


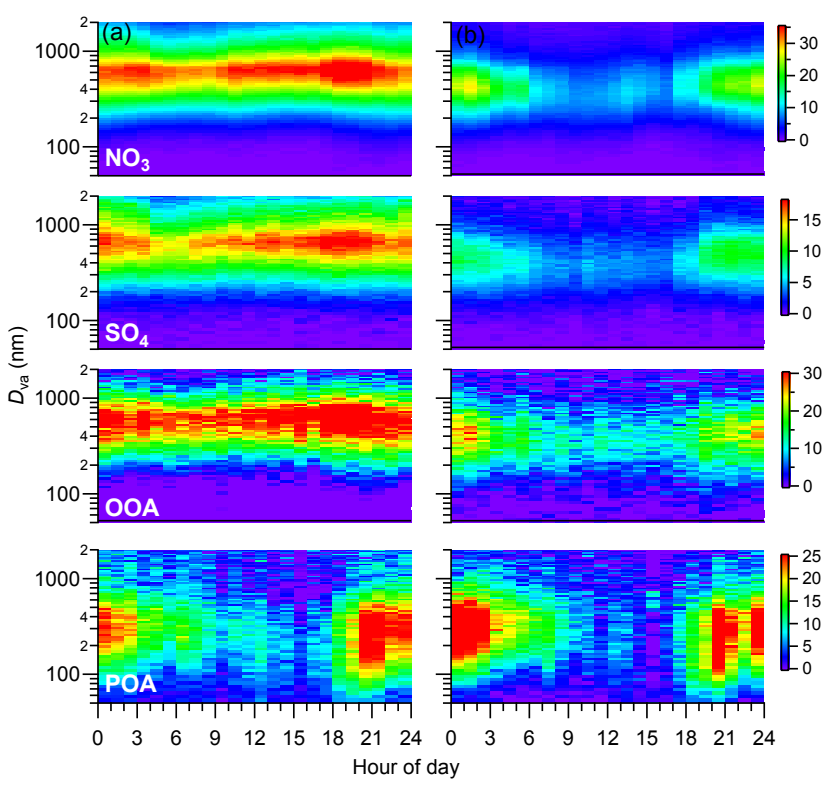

Figure 8. Diurnal evolution of the size distributions of NR-PM species measured (a) before the Asia-Pacific Economic Cooperation (APEC) and (b) during APEC.

$(\sim 400 \mathrm{~nm})$. These results demonstrate that emission controls of secondary aerosol precursors exerted a dominant impact on accumulation-mode particles. As indicated in Fig. 1, the duration time of pollution episodes before APEC was overall longer than that during APEC, indicating that secondary aerosol was less aged during APEC. This might also explained the smaller size of secondary aerosol species during APEC. In addition, we noted that the average RH during APEC was $37 \%$, which is lower than $53 \%$ recorded before APEC. The relatively drier conditions during APEC also played a role in suppressing particle growth. Indeed, clear particle growth was observed during three episodes before APEC, although it was insignificant during APEC. Comparatively, the size distribution of POA remained relatively unchanged, indicating the presence of strong local source emissions during APEC. This result is consistent with the significantly smaller reductions of primary species than those of secondary species during APEC. Although the contribution of POA to NR-PM ${ }_{1}$ showed a rapid decrease as a function of diameter, it still constituted a considerable fraction $(\sim 30 \%)$ at particle sizes larger than $30 \mathrm{~nm}$. These results suggested that POA played an important role in PM pollution during APEC as a result of large reductions of secondary aerosol.

As indicated in Fig. 8, SIA and SOA showed consistently large accumulation modes at $\sim 500-800 \mathrm{~nm}$ throughout the day before APEC. This result is consistent with the fact that SIA and SOA were formed mainly over a regional scale and were relatively well processed in the atmosphere. Slight increases in particle diameters in the afternoon were also observed for SIA and SOA, indicating the role of photo- chemical processing. In contrast, SIA and SOA shifted to smaller sizes at $\sim 300-600 \mathrm{~nm}$ at various times of the day during APEC with the mass concentrations above $200 \mathrm{~nm}$ showing substantial decreases. As previously discussed, such changes in size and mass during APEC are the combined results of emission controls and meteorological effects. The POA showed significant differences in size evolution behavior from secondary aerosol. The POA size distribution was similar before and during APEC, both characterized by higher concentration at nighttime (19:00-03:00) with a peak diameter at $\sim 300 \mathrm{~nm}$. Moreover, a considerable fraction of POA particles was found in ultrafine mode $(<100 \mathrm{~nm})$, particularly in the evening time, indicating local fresh primary emissions. It is worth noting that POA during APEC showed higher mass concentrations between 00:00 and 03:00 than that before APEC, coinciding with a time without traffic control, and likely having more traffic emissions during APEC.

\subsection{Elemental composition of $\mathrm{OA}$}

Figure 9 shows the time series of elemental ratios for the entire study period. The $\mathrm{O} / \mathrm{C}$ ratio, an indicator of the oxidation degree of OA, varied significantly from 0.11 to 0.72 , indicating large variations of oxidation properties of $\mathrm{OA}$ in this study. The average $\mathrm{O} / \mathrm{C}$ for the entire study was 0.41 , which is higher than that observed at other urban sites in China, at 0.31-0.33 (He et al., 2011; Huang et al., 2012; $\mathrm{Xu}$ et al., 2014; Zhang et al., 2015), yet lower than those measured at rural/remote sites (Huang et al., 2011; Hu et al., 2013). These results indicate that the OA in this study was aged more than that at other urban sites in China. The $\mathrm{OM} / \mathrm{OC}$ ratio showed similar variations as those of $\mathrm{O} / \mathrm{C}$ $\left(R^{2}=0.99\right)$, varying between 1.30 and 2.16 with an average value of $1.7( \pm 0.17)$. The average OM / OC was slightly higher than the $1.6 \pm 0.2$ value for urban OA recommended by Turpin and Lim (2001), and the value of 1.6 previously reported in urban Beijing (Huang et al., 2010a; Zhang et al., 2015). The average $\mathrm{O} / \mathrm{C}$ and $\mathrm{OM} / \mathrm{OC}$ during APEC were $0.36( \pm 0.10)$ and $1.64( \pm 0.13)$, respectively, which are lower than 0.43 and 1.75 before APEC, demonstrating a decrease in oxidation degree of OA during APEC. These results are consistent with the OA composition change during APEC, which showed a substantial decrease in SOA and a corresponding increase in POA. Figure 9 also shows that the $\mathrm{O} / \mathrm{C}$ ratio exhibited a continuous increase during three severe pollution episodes on 17-20, 23-25, and 29-31 October with the exception of occasional decreases due to the influences of local POA. These results suggest that OA can be aged to a high degree $(\mathrm{O} / \mathrm{C}>0.6)$ during the evolution of severe air pollution. In contrast, such an aging process of OA was observed to be insignificant during APEC.

Both $\mathrm{H} / \mathrm{C}$ and $\mathrm{O} / \mathrm{C}$ ratios showed pronounced diurnal cycles before and during APEC (Fig. 9c, d). The O/C ratio showed a gradual increase and reached a maximum value of 0.55 at 16:00 before APEC, indicating the photochemi- 

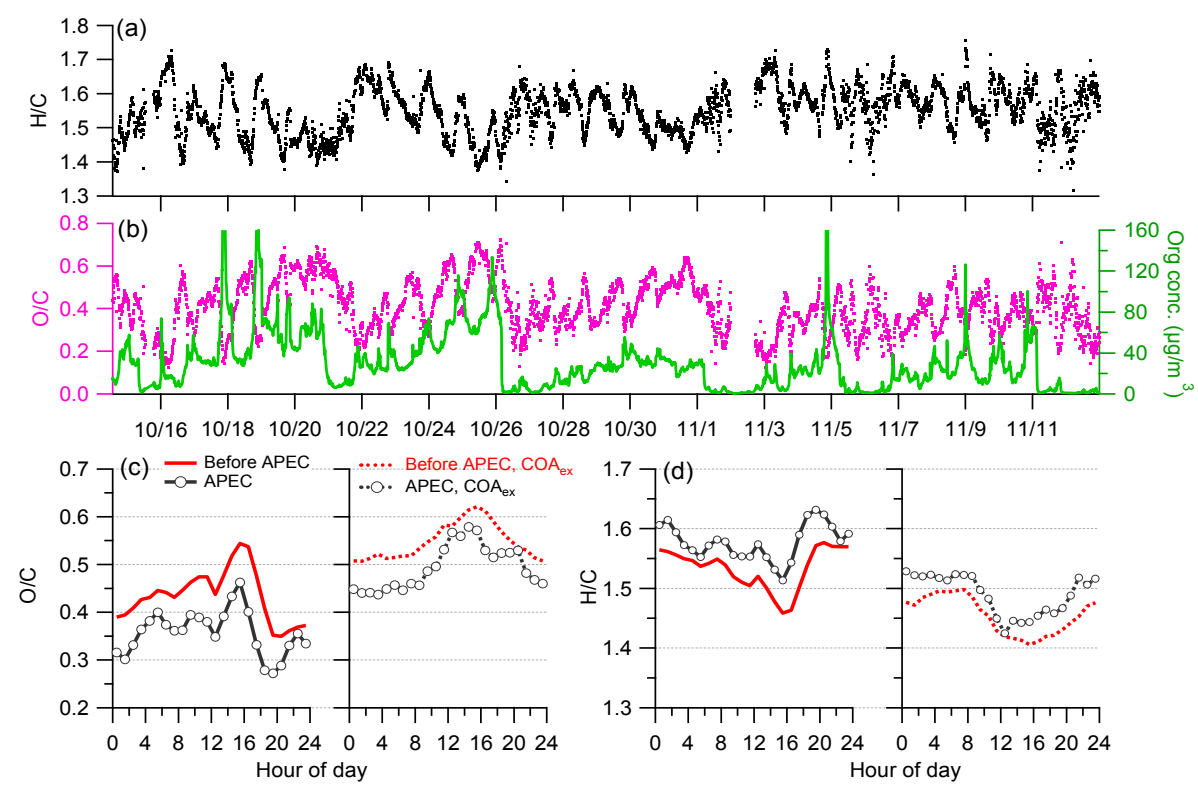

Figure 9. Time series of (a) $\mathrm{H} / \mathrm{C}$, (b) $\mathrm{O} / \mathrm{C}$, and organics, and diurnal variations of (c) $\mathrm{O} / \mathrm{C}$ and (d) $\mathrm{H} / \mathrm{C}$. The dashed lines in (c) and (d) indicate the elemental ratios by excluding the contributions from cooking aerosols.

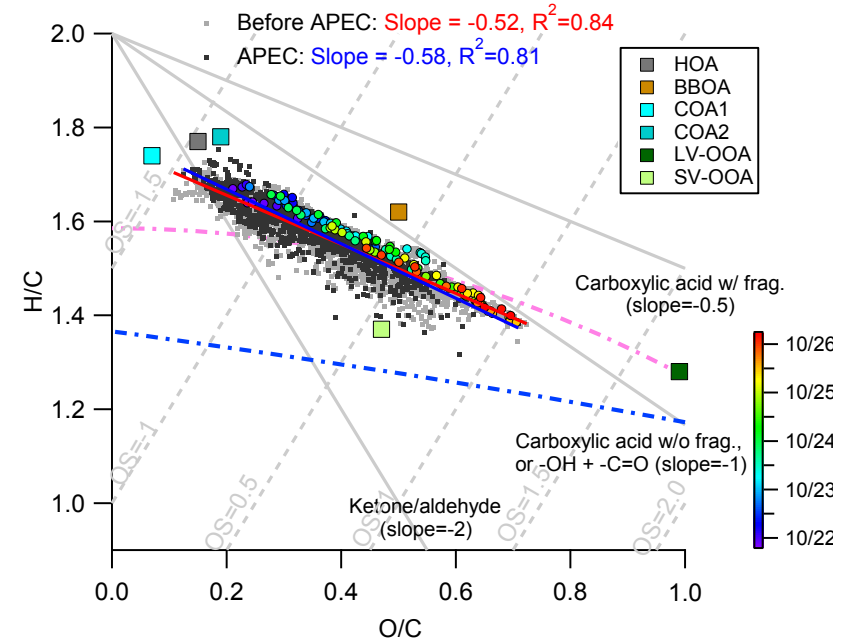

Figure 10. Van Krevelen diagram of $\mathrm{H} / \mathrm{C}$ vs. O C . The dashed lines indicate changes in $\mathrm{H} / \mathrm{C}$ against $\mathrm{O} / \mathrm{C}$ due to the addition of specific functional groups to aliphatic carbon (Heald et al., 2010). The pink and blue lines are derived from the right and left lines in the triangle plot of positive matrix factorization (PMF) determined from 43 sites in the Northern Hemisphere ( $\mathrm{Ng}$ et al., 2011). The color-coded $\mathrm{H} / \mathrm{C}$ vs. $\mathrm{O} / \mathrm{C}$ refers to the data measured during the severe haze episode shown in Fig. 12.

cal aging processes of OA. Such a photochemical driven diurnal variation of $\mathrm{O} / \mathrm{C}$ was also observed at various sites in China (He et al., 2011; Xu et al., 2014; Zhang et al., 2015). The $\mathrm{O} / \mathrm{C}$ also showed a temporal decrease at three times, corresponding to cooking activities. This result indicates that cooking aerosol can significantly influence the bulk oxidation degree of OA. Indeed, the diurnal variation of $\mathrm{O} / \mathrm{C}$ ratio after excluding COA contributions was markedly smoother, varying from 0.5 to 0.65 . The $\mathrm{O} / \mathrm{C}$ ratio during APEC showed a diurnal pattern similar to that before APEC yet with lower values by $\sim 0.1$ throughout the day. This result illustrates that the photochemical aging of OA was significantly less pronounced during APEC. The $\mathrm{H} / \mathrm{C}$ ratios showed opposite diurnal cycles as those of $\mathrm{O} / \mathrm{C}$ before and during APEC (Fig. 9).

Figure 10 shows a van Krevelen diagram for illustrating the evolution of OA before and during APEC. The aging of $\mathrm{OA}$ is generally characterized by an increase in $\mathrm{O} / \mathrm{C}$ and a decrease in $\mathrm{H} / \mathrm{C}$. The different aging mechanisms of $\mathrm{OA}$ follow different slopes. Although $\mathrm{H} / \mathrm{C}$ correlated strongly with $\mathrm{O} / \mathrm{C}$ before and during APEC $\left(R^{2}=0.84\right.$ and 0.81 , respectively), the regression slopes differed. The slope of $\mathrm{H} / \mathrm{C}$ vs. $\mathrm{O} / \mathrm{C}$ during APEC was -0.58 , which is steeper than -0.52 measured before APEC. This result indicates their slightly different aging processes are mainly driven by the additions of carboxylic acid with fragmentation ( $\mathrm{Ng}$ et al., 2011). The slope in this study is less than that measured in Changdao at -0.63 (Hu et al., 2013), Shenzhen at -0.87 (He et al., 2011), and Kaiping in PRD at -0.76 (Huang et al., 2011), indicating that the aging mechanism of OA varies among different sites and seasons in China.

As shown in Fig. 11a, the $\mathrm{O} / \mathrm{C}$ varied dramatically and showed no clear dependence on RH at low RH levels of $<60 \%$, although a positive increase as a function of RH before APEC was observed at RH $>60 \%$. These results might indicate that aqueous-phase processing at high RH levels increased the oxidation degree of OA. The POA with a high 


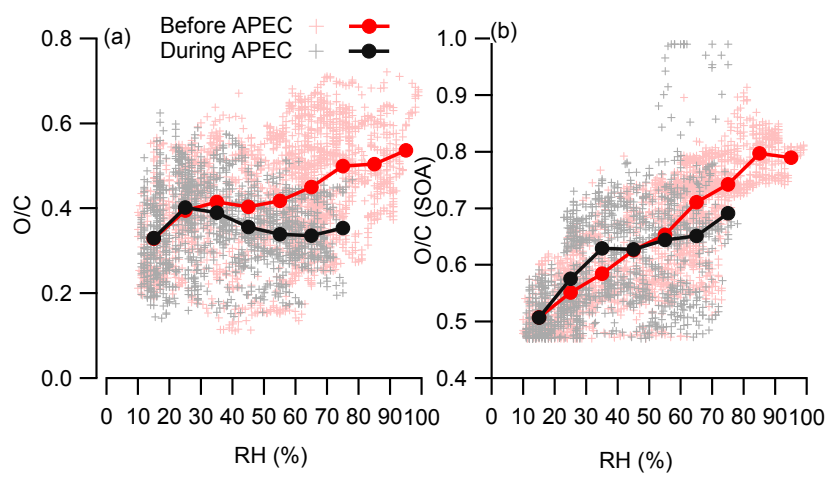

Figure 11. Variations in (a) $\mathrm{O} / \mathrm{C}$ and (b) $\mathrm{O} / \mathrm{C}$ of secondary organic aerosol (SOA) as a function of relative humidity $(\mathrm{RH})$ measured (a) before the Asia-Pacific Economic Cooperation (APEC) summit and (b) during APEC. The data are also binned according to RH with increments of $10 \%$.

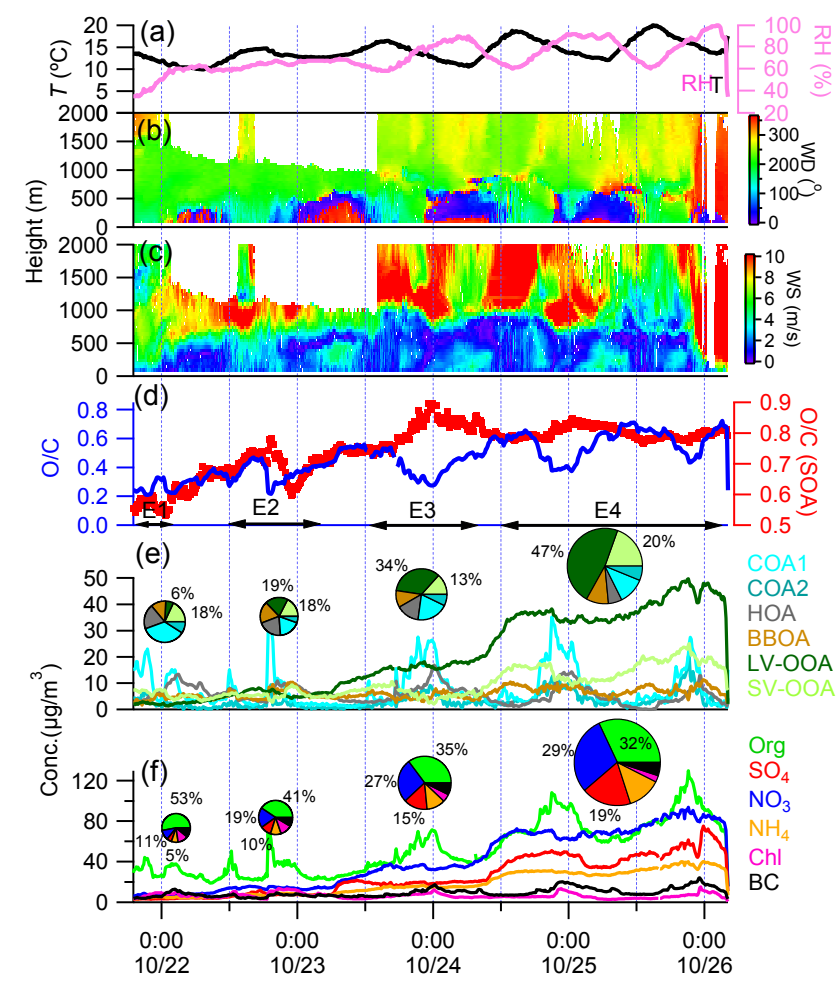

Figure 12. Evolution of meteorological variables including (ac) relative humidity $(\mathrm{RH})$, temperature $(T)$, and vertical profiles of wind direction (WD) and wind speed (WS); (d) $\mathrm{O} / \mathrm{C}$ and $\mathrm{O} / \mathrm{C}$ of secondary organic aerosol (SOA); (e) organic aerosol (OA) factors; and (f) $\mathrm{PM}_{1}$ species. The pie charts show the average chemical composition of $\mathrm{PM}_{1}$ and $\mathrm{OA}$ for each stage. The numbers on the pie charts show the contributions of (e) semi-volatile oxygenated organic aerosol (SV-OOA) and low-volatility oxygenated organic aerosol (LV-OOA) and (f) organics, nitrate, and sulfate.

concentration at nighttime when $\mathrm{RH}$ is correspondingly high can have a large influence on the $\mathrm{O} / \mathrm{C}$ of total $\mathrm{OA}$, which explains the slight decrease in $\mathrm{O} / \mathrm{C}$ as a function of $\mathrm{RH}$ during APEC. The $\mathrm{O} / \mathrm{C}$ ratio of SOA was calculated, and its relationship with $\mathrm{RH}$ is shown in Fig. 11b. It is clear that the $\mathrm{O} / \mathrm{C}$ ratio of SOA rapidly increased from 0.5 to 0.8 as the $\mathrm{RH}$ increased from $10 \%$ to $>80 \%$ before APEC. The $\mathrm{O} / \mathrm{C}$ of SOA showed similar RH dependence during APEC. Such an increase is mainly caused by a faster increase of LVOOA than that of SV-OOA. These results likely indicate that aqueous-phase processing produced highly aged OA during the severe haze pollution episodes. However, we found that LV-OOA tightly correlated with $\mathrm{NO}_{3}\left(R^{2}=0.94\right)$, whereas aqueous-phase production appeared to play an insignificant role in nitrate formation during winter (Sun et al., 2013). Therefore, the highly aged OA at high $\mathrm{RH}$ levels was more likely due to the aging of LV-OOA for a longer time during the transport to Beijing. Further studies are needed to investigate the role of aqueous-phase processing in the alteration of the oxidation properties of OA.

\subsection{Case study of the evolution of a severe haze episode}

The 4-day evolution of a severe pollution episode was observed between 22 and 25 October, during which the average $\mathrm{PM}_{1}$ concentration showed a 10 -fold increase from $<30$ to $>300 \mu \mathrm{g} \mathrm{m}^{-3}$. As shown in Fig. 12, this evolution period was characterized by prevailing southerly winds and air masses (Fig. S5), low WS $\left(<4 \mathrm{~m} \mathrm{~s}^{-1}\right)$ across the entire layer below $500 \mathrm{~m}$, and also relatively high RH (> 50\%). Routine circulations of mountain-valley breeze from the northwest and the northeast that occurred at midnight and dissipated at noon were also observed. However, the mountain-valley breeze did not appear to significantly affect the evolution of this haze episode likely because it was a regional haze event with a high PM concentration in the entire region of the North China (Fig. S4).

The evolution of this haze episode can be classified into four stages with different aerosol composition and oxidation properties. The aerosol composition during the early formation stage (E1) was dominated by organics (53\%) with a small contribution from SIA $(23 \%)$. The OA showed dominant contributions from cooking $(45 \%)$ and traffic $(19 \%)$ sources, indicating that local sources played the most significant roles during this stage. Consistently, OA showed fresh properties with an average $\mathrm{O} / \mathrm{C}$ ratio of 0.25 . The aerosol composition had a substantial change during stage 2 (E2). Although the contribution of organics decreased to $41 \%$, those of sulfate and nitrate increased nearly by a factor of 2 (10 and $19 \%$, respectively). The $\mathrm{O} / \mathrm{C}$ ratio of $\mathrm{OA}$ increased from $\sim 0.2$ to $\sim 0.5$, suggesting the occurrence of more aged air masses during E2. Indeed, the contribution of LV-OOA showed a great enhancement from 6 to $19 \%$, whereas that of SV-OOA exhibited minor changes. As this haze episode progressed (stage 3, E3), SIA exceeded organics and became the dominant component in $\mathrm{PM}_{1}(53 \%)$; in particular, nitrate accounted for nearly one-third of the total 
$\mathrm{PM}_{1}$ mass. These results highlight the enhanced roles of SIA in severe haze episodes, which are consistent with the conclusions drawn in many previous studies in China (Huang et al., 2014; Sun et al., 2014). OA was further aged during this stage with the $\mathrm{O} / \mathrm{C}$ ratio approaching 0.6 , and the highly oxidized LV-OOA accounting for nearly one-third of the total OA. The haze episode evolved further at 10:00 on 24 October with a large enhancement of $\mathrm{PM}_{1}$ from $\sim 150$ to $>200 \mu \mathrm{g} \mathrm{m}^{-3}$, which remained consistently high for 1.5 days (stage 4, E4). The aerosol composition during this stage remained relatively constant. SIA contributed more than $60 \%$ of the total $\mathrm{PM}_{1}$, and SOA accounted for $67 \%$ of the total $\mathrm{OA}$, which together contributed $82 \%$ of the total $\mathrm{PM}_{1}$, further elucidating the significant role of secondary aerosol in haze formation.

Although SIA was observed to gradually increase during the evolution of this haze episode, primary aerosol species such as COA, HOA, and BC showed similar diurnal variations during $\mathrm{E} 3$ and $\mathrm{E} 4$, indicating relatively constant local emissions during these two stages. Although the daily maximum of $\mathrm{O} / \mathrm{C}$ showed a continuous increase, pronounced diurnal cycles with the lowest values occurring at midnight were also observed due to the influences of local primary OA. The $\mathrm{O} / \mathrm{C}$ of SOA was then calculated for a better illustration of OA aging. As shown in Fig. 12d, the $\mathrm{O} / \mathrm{C}$ ratio of SOA showed a gradual increase from $\sim 0.55$ to 0.8 during E1-E3 and remained consistently high $(\sim 0.8)$ during E4. This result is consistent with the relative contributions of LV-OOA and SV-OOA during the four evolution stages. Although SVOOA was higher than LV-OOA during E1, LV-OOA gradually exceeded SV-OOA and became the dominant contributor of OA during the following three stages. These results illustrate that the aging of the haze episode was associated with significant formation of highly oxidized OA. The van Krevelen diagram of $\mathrm{H} / \mathrm{C}$ vs. $\mathrm{O} / \mathrm{C}$ for this haze episode is shown in Fig. 10. It is clear that $\mathrm{OA}$ evolved rapidly during this haze episode, showing an increase in $\mathrm{O} / \mathrm{C}$ associated with a corresponding decrease in $\mathrm{H} / \mathrm{C}$ with a slope of -0.6.

Figure 13 shows the evolution of size distributions of sulfate, nitrate, and organics during this haze episode. Sulfate and nitrate showed evident particle growth as a function of time. Although broad size distributions peaking at $\sim 350 \mathrm{~nm}$ were observed during E1, the peak diameters gradually evolved to $\sim 700 \mathrm{~nm}$ during E4; these size distributions were characterized by single large accumulation modes. Organics showed similar size evolution behavior as that of sulfate and nitrate but presented significant contributions from particles smaller than $200 \mathrm{~nm}$. In particular, the influences of local primary emissions such as cooking and traffic on small particles were observed at nighttime during 23-25 October. Overall, the aerosol composition, oxidation properties, and size distributions exhibited substantial changes during the evolution of the severe haze episode, which was characterized by the significant enhancement of SIA and SOA with high oxidation degrees and large particle diameters.
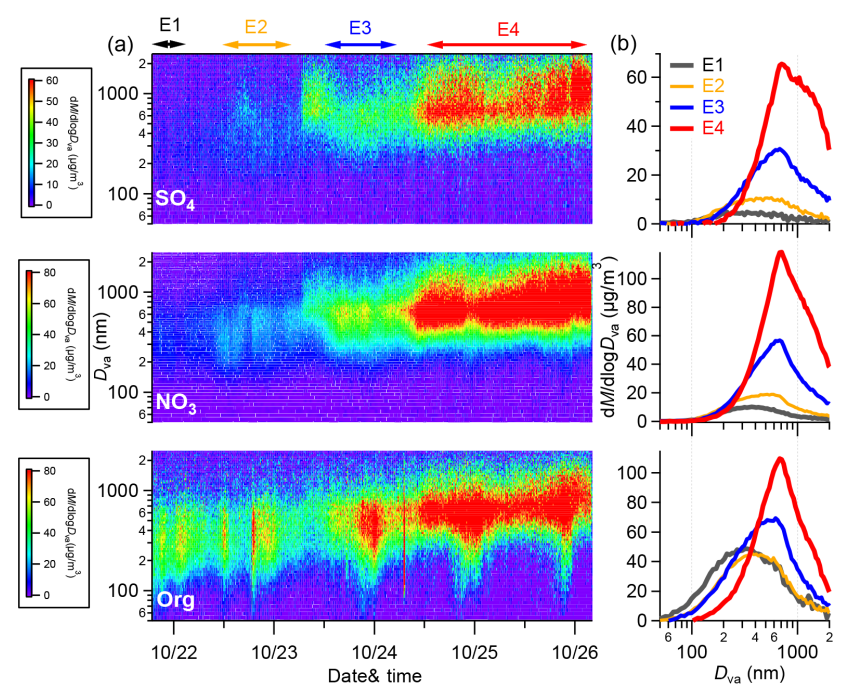

Figure 13. (a) Evolution of size distributions of sulfate, nitrate, and organics during the severe haze episode between 22 and 25 October (Fig. 12). (b) Average size distributions of sulfate, nitrate, and organics during the four stages of E1-E4.

\section{Conclusions}

China imposed strict emission controls in Beijing and its surrounding regions during the 2014 APEC summit. In this study, we present a detailed investigation of the impacts of emission controls on the changes in chemical composition, oxidation properties, and size distributions of submicron aerosols. The average mass concentration of $\mathrm{PM}_{1}$ showed a substantial decrease from $88.0 \mu \mathrm{g} \mathrm{m}^{-3}$ before APEC to $41.6 \mu \mathrm{g} \mathrm{m}^{-3}$ during APEC. The aerosol composition also showed significant changes. Although submicron aerosols were composed mainly of organics, at $38.0 \%$, followed by nitrate at $26.4 \%$ and sulfate at $13.7 \%$ before APEC, the contribution of organics was observed to have a significant increase at $52.4 \%$ associated with a significant reduction of SIA during APEC. This result demonstrates the different responses of SIA and OA to regional emission controls. PMF analysis of OA identified three primary sources including traffic, cooking, and biomass-burning emissions and two secondary factors with different oxidation degrees. The highly oxidized LV-OOA showed reductions similar to those of SIA with the contribution to OA decreasing from 30 to $14 \%$. In contrast, POA showed elevated contributions indicating the presence of strong local source emissions during APEC. The $\mathrm{O} / \mathrm{C}$ ratio of OA decreased from 0.43 to 0.36 , demonstrating a decrease in the oxidization degree of OA during APEC. The peak diameters in size distributions of SIA and SOA were $\sim 650 \mathrm{~nm}$ or even larger before APEC and shifted to smaller sizes of $\sim 400 \mathrm{~nm}$ during APEC. This result illustrates that emission controls of secondary aerosol precursors exerted a dominant impact in reducing accumulation-mode particles. Comparatively, the size distributions of POA remained rel- 
atively unchanged. Therefore, our results elucidated significant changes in chemical composition, size distributions, and oxidation properties of aerosol particles as a result of emission controls and meteorological effects. In addition, we observed significant changes in aerosol properties during the aging processes of a severe haze pollution episode, which was typically characterized by a gradual increase of SIA and SOA with higher oxidation degrees and large particle diameters. Note that the routine circulation of a mountain-valley breeze during APEC was also observed to play a role in achieving "APEC blue" by conditions reducing PM levels substantially during daytime. Despite the fact that controlling secondary aerosol precursors over regional scales can substantially reduce secondary particulates, stricter controls of local source emissions are needed for further mitigation of air pollution in Beijing.

\section{The Supplement related to this article is available online at doi:10.5194/acp-15-13681-2015-supplement.}

Acknowledgements. This work was supported by the National Key Project of Basic Research (2014CB447900), the National Natural Science Foundation of China (41305130, 41175108), the Strategic Priority Research Program (B) of the Chinese Academy of Sciences (XDB05020501), the Key Research Program of the Chinese Academy of Sciences (KJZD-EW-TZ-G06-01-0), and the Special Funds for Scientific Research on Public Welfare (201409001).

Edited by: N. L. Ng

\section{References}

Aiken, A. C., DeCarlo, P. F., and Jimenez, J. L.: Elemental analysis of organic species with electron ionization high-resolution mass spectrometry, Anal. Chem., 79, 8350-8358, 2007.

Aiken, A. C., Salcedo, D., Cubison, M. J., Huffman, J. A., DeCarlo, P. F., Ulbrich, I. M., Docherty, K. S., Sueper, D., Kimmel, J. R., Worsnop, D. R., Trimborn, A., Northway, M., Stone, E. A., Schauer, J. J., Volkamer, R. M., Fortner, E., de Foy, B., Wang, J., Laskin, A., Shutthanandan, V., Zheng, J., Zhang, R., Gaffney, J., Marley, N. A., Paredes-Miranda, G., Arnott, W. P., Molina, L. T., Sosa, G., and Jimenez, J. L.: Mexico City aerosol analysis during MILAGRO using high resolution aerosol mass spectrometry at the urban supersite (T0) - Part 1: Fine particle composition and organic source apportionment, Atmos. Chem. Phys., 9, 6633-6653, doi:10.5194/acp-9-6633-2009, 2009.

Alfarra, M. R., Prevot, A. S. H., Szidat, S., Sandradewi, J., Weimer, S., Lanz, V. A., Schreiber, D., Mohr, M., and Baltensperger, U.: Identification of the mass spectral signature of organic aerosols from wood burning emissions, Environ. Sci. Technol., 41, 5770$5777,2007$.
Allan, J. D., Jimenez, J. L., Williams, P. I., Alfarra, M. R., Bower, K. N., Jayne, J. T., Coe, H., and Worsnop, D. R.: Quantitative sampling using an Aerodyne Aerosol Mass Spectrometer. Part 1: Techniques of data interpretation and error analysis, J. Geophys. Res.-Atmos., 108, 4090, doi:4010.1029/2002JD002358, 2003.

Canagaratna, M. R., Jimenez, J. L., Kroll, J. H., Chen, Q., Kessler, S. H., Massoli, P., Hildebrandt Ruiz, L., Fortner, E., Williams, L. R., Wilson, K. R., Surratt, J. D., Donahue, N. M., Jayne, J. T., and Worsnop, D. R.: Elemental ratio measurements of organic compounds using aerosol mass spectrometry: characterization, improved calibration, and implications, Atmos. Chem. Phys., 15, 253-272, doi:10.5194/acp-15-253-2015, 2015.

Cao, J. J., Wu, F., Chow, J. C., Lee, S. C., Li, Y., Chen, S. W., An, Z. S., Fung, K. K., Watson, J. G., Zhu, C. S., and Liu, S. X.: Characterization and source apportionment of atmospheric organic and elemental carbon during fall and winter of 2003 in Xi' an, China, Atmos. Chem. Phys., 5, 3127-3137, doi:10.5194/acp-53127-2005, 2005.

Cermak, J. and Knutti, R.: Beijing Olympics as an aerosol field experiment, Geophys. Res. Lett., 36, L10806 doi:10.1029/2009g1038572, 2009.

Chen, C., Sun, Y. L., Xu, W. Q., Du, W., Zhou, L. B., Han, T. T., Wang, Q. Q., Fu, P. Q., Wang, Z. F., Gao, Z. Q., Zhang, Q., and Worsnop, D. R.: Characteristics and sources of submicron aerosols above the urban canopy $(260 \mathrm{~m})$ in Beijing, China, during the 2014 APEC summit, Atmos. Chem. Phys., 15, 12879 12895, doi:10.5194/acp-15-12879-2015, 2015.

Chow, J. C., Bachmann, J. D., Wierman, S. S. G., Mathai, C. V., Malm, W. C., White, W. H., Mueller, P. K., Kumar, N., and Watson, J. G.: Visibility: Science and Regulation, J. Air Waste Manage., 52, 973-999, doi:10.1080/10473289.2002.10470844, 2002.

Cubison, M. J., Ortega, A. M., Hayes, P. L., Farmer, D. K., Day, D., Lechner, M. J., Brune, W. H., Apel, E., Diskin, G. S., Fisher, J. A., Fuelberg, H. E., Hecobian, A., Knapp, D. J., Mikoviny, T., Riemer, D., Sachse, G. W., Sessions, W., Weber, R. J., Weinheimer, A. J., Wisthaler, A., and Jimenez, J. L.: Effects of aging on organic aerosol from open biomass burning smoke in aircraft and laboratory studies, Atmos. Chem. Phys., 11, 12049-12064, doi:10.5194/acp-11-12049-2011, 2011.

Dan, M., Zhuang, G., Li, X., Tao, H., and Zhuang, Y.: The characteristics of carbonaceous species and their sources in $\mathrm{PM}_{2.5}$ in Beijing, Atmos. Environ., 38, 3443-3452, 2004.

DeCarlo, P. F., Ulbrich, I. M., Crounse, J., de Foy, B., Dunlea, E. J., Aiken, A. C., Knapp, D., Weinheimer, A. J., Campos, T., Wennberg, P. O., and Jimenez, J. L.: Investigation of the sources and processing of organic aerosol over the Central Mexican Plateau from aircraft measurements during MILAGRO, Atmos. Chem. Phys., 10, 5257-5280, doi:10.5194/acp-10-52572010, 2010.

Drewnick, F., Hings, S. S., DeCarlo, P., Jayne, J. T., Gonin, M., Fuhrer, K., Weimer, S., Jimenez, J. L., Demerjian, K. L., Borrmann, S., and Worsnop, D. R.: A New Time-of-Flight Aerosol Mass Spectrometer (TOF-AMS) - Instrument Description and First Field Deployment, Aerosol Sci. Tech., 39, 637658, doi:10.1080/02786820500182040, 2005.

Forster, P., Ramaswamy, V., Artaxo, P., Berntsen, T., Betts, R., Fahey, D. W., Haywood, J., Lean, J., Lowe, D. C., Myhre, G., Nganga, J., Prinn, R., Raga, G., Schulz, M., and Dorland, R. V.: Changes in Atmospheric Constituents and in Radiative Forcing. 
in: Climate Change 2007: The Physical Science Basis. Contribution of Working Group I to the Fourth Assessment Report of the Intergovernmental Panel on Climate Change, edited by: Solomon, S., Qin, D., Manning, M., Chen, Z., Marquis, M., Averyt, K. B., Tignor, M., and Miller, H. L., Cambridge University Press, Cambridge, UK and New York, NY, USA, 2007.

Ge, X., Setyan, A., Sun, Y., and Zhang, Q.: Primary and secondary organic aerosols in Fresno, California during wintertime: Results from high resolution aerosol mass spectrometry, J. Geophys. Res., 117, D19301, doi:10.1029/2012JD018026, 2012a.

Ge, X., Zhang, Q., Sun, Y., Ruehl, C. R., and Setyan, A.: Effect of aqueous-phase processing on aerosol chemistry and size distributions in Fresno, California, during wintertime, Environ. Chem., 9, 221-235, doi:10.1071/en11168, 2012b.

Guo, S., Hu, M., Guo, Q., Zhang, X., Zheng, M., Zheng, J., Chang, C.-C., Schauer, J. J., and Zhang, R.: Primary Sources and Secondary Formation of Organic Aerosols in Beijing, China, Environ. Sci. Technol., 46, 9846-9853, doi:10.1021/es2042564, 2012.

Guo, S., Hu, M., Guo, Q., Zhang, X., Schauer, J. J., and Zhang, R.: Quantitative evaluation of emission controls on primary and secondary organic aerosol sources during Beijing 2008 Olympics, Atmos. Chem. Phys., 13, 8303-8314, doi:10.5194/acp-13-83032013, 2013.

Han, S., Kondo, Y., Oshima, N., Takegawa, N., Miyazaki, Y., Hu, M., Lin, P., Deng, Z., Zhao, Y., Sugimoto, N., and Wu, Y.: Temporal variations of elemental carbon in Beijing, J. Geophys. Res., 114, D23202, doi:10.1029/2009jd012027, 2009.

He, L.-Y., Lin, Y., Huang, X.-F., Guo, S., Xue, L., Su, Q., Hu, M., Luan, S.-J., and Zhang, Y.-H.: Characterization of highresolution aerosol mass spectra of primary organic aerosol emissions from Chinese cooking and biomass burning, Atmos. Chem. Phys., 10, 11535-11543, doi:10.5194/acp-10-11535-2010, 2010.

He, L.-Y., Huang, X.-F., Xue, L., Hu, M., Lin, Y., Zheng, J., Zhang, R., and Zhang, Y.-H.: Submicron aerosol analysis and organic source apportionment in an urban atmosphere in Pearl River Delta of China using high-resolution aerosol mass spectrometry, J. Geophys. Res., 116, D12304, doi:10.1029/2010jd014566, 2011.

Heald, C. L., Kroll, J. H., Jimenez, J. L., Docherty, K. S., DeCarlo, P. F., Aiken, A. C., Chen, Q., Martin, S. T., Farmer, D. K., and Artaxo, P.: A simplified description of the evolution of organic aerosol composition in the atmosphere, Geophys. Res. Lett., 37, L08803, doi:10.1029/2010g1042737, 2010.

Hu, W. W., Hu, M., Yuan, B., Jimenez, J. L., Tang, Q., Peng, J. F., Hu, W., Shao, M., Wang, M., Zeng, L. M., Wu, Y. S., Gong, Z. H., Huang, X. F., and He, L. Y.: Insights on organic aerosol aging and the influence of coal combustion at a regional receptor site of central eastern China, Atmos. Chem. Phys., 13, 10095-10112, doi:10.5194/acp-13-10095-2013, 2013.

Huang, R. J., Zhang, Y., Bozzetti, C., Ho, K. F., Cao, J. J., Han, Y., Daellenbach, K. R., Slowik, J. G., Platt, S. M., Canonaco, F., Zotter, P., Wolf, R., Pieber, S. M., Bruns, E. A., Crippa, M., Ciarelli, G., Piazzalunga, A., Schwikowski, M., Abbaszade, G., SchnelleKreis, J., Zimmermann, R., An, Z., Szidat, S., Baltensperger, U., El Haddad, I., and Prevot, A. S.: High secondary aerosol contribution to particulate pollution during haze events in China, Nature, 514, 218-222, doi:10.1038/nature13774, 2014.
Huang, X.-F., Xue, L., He, L., Hu, M., Zhang, Y., and Zhu, T.: On-line measurement of organic aerosol elemental composition based on high resolution aerosol mass spectrometry, Chinese Sci. Bull., 55, 3391-3396, doi:10.1360/972010-1322, 2010a (in Chinese).

Huang, X.-F., He, L.-Y., Hu, M., Canagaratna, M. R., Sun, Y., Zhang, Q., Zhu, T., Xue, L., Zeng, L.-W., Liu, X.-G., Zhang, Y.-H., Jayne, J. T., Ng, N. L., and Worsnop, D. R.: Highly time-resolved chemical characterization of atmospheric submicron particles during 2008 Beijing Olympic Games using an Aerodyne High-Resolution Aerosol Mass Spectrometer, Atmos. Chem. Phys., 10, 8933-8945, doi:10.5194/acp-10-8933-2010, 2010 b.

Huang, X.-F., He, L.-Y., Hu, M., Canagaratna, M. R., Kroll, J. H., Ng, N. L., Zhang, Y.-H., Lin, Y., Xue, L., Sun, T.-L., Liu, X.-G., Shao, M., Jayne, J. T., and Worsnop, D. R.: Characterization of submicron aerosols at a rural site in Pearl River Delta of China using an Aerodyne High-Resolution Aerosol Mass Spectrometer, Atmos. Chem. Phys., 11, 1865-1877, doi:10.5194/acp-11-18652011, 2011.

Huang, X.-F., He, L.-Y., Xue, L., Sun, T.-L., Zeng, L.-W., Gong, Z.-H., Hu, M., and Zhu, T.: Highly time-resolved chemical characterization of atmospheric fine particles during 2010 Shanghai World Expo, Atmos. Chem. Phys., 12, 4897-4907, doi:10.5194/acp-12-4897-2012, 2012.

Huang, X.-F., Xue, L., Tian, X.-D., Shao, W.-W., Sun, T.-L., Gong, Z.-H., Ju, W.-W., Jiang, B., Hu, M., and He, L.Y.: Highly time-resolved carbonaceous aerosol characterization in Yangtze River Delta of China: Composition, mixing state and secondary formation, Atmos. Environ., 64, 200-207, doi:10.1016/j.atmosenv.2012.09.059, 2013.

Jayne, J. T., Leard, D. C., Zhang, X., Davidovits, P., Smith, K. A., Kolb, C. E., and Worsnop, D. R.: Development of an aerosol mass spectrometer for size and composition analysis of submicron particles, Aerosol Sci. Tech., 33, 49-70, 2000.

Jiang, Q., Sun, Y. L., Wang, Z., and Yin, Y.: Aerosol composition and sources during the Chinese Spring Festival: fireworks, secondary aerosol, and holiday effects, Atmos. Chem. Phys., 15, 6023-6034, doi:10.5194/acp-15-6023-2015, 2015.

Jimenez, J. L.: Ambient aerosol sampling using the Aerodyne Aerosol Mass Spectrometer, J. Geophys. Res., 108, 8425, doi:10.1029/2001jd001213, 2003.

Lee, B. P., Li, Y. J., Yu, J. Z., Louie, P. K. K., and Chan, C. K.: Physical and chemical characterization of ambient aerosol by HR-ToF-AMS at a suburban site in Hong Kong during springtime 2011, J. Geophys. Res.-Atmos., 118, 8625-8639, doi:10.1002/jgrd.50658, 2013.

Levin, E. J. T., McMeeking, G. R., Carrico, C. M., Mack, L. E., Kreidenweis, S. M., Wold, C. E., Moosmüller, H., Arnott, W. P., Hao, W. M., Collett Jr., J. L., and Malm, W. C.: Biomass burning smoke aerosol properties measured during Fire Laboratory at Missoula Experiments (FLAME), J. Geophys. Res., 115, D18210, doi:10.1029/2009jd013601, 2010.

Matthew, B. M., Middlebrook, A. M., and Onasch, T. B.: Collection Efficiencies in an Aerodyne Aerosol Mass Spectrometer as a Function of Particle Phase for Laboratory Generated Aerosols, Aerosol Sci. Tech., 42, 884-898, doi:10.1080/02786820802356797, 2008. 
Middlebrook, A. M., Bahreini, R., Jimenez, J. L., and Canagaratna, M. R.: Evaluation of Composition-Dependent Collection Efficiencies for the Aerodyne Aerosol Mass Spectrometer using Field Data, Aerosol Sci. Tech., 46, 258-271, doi:10.1080/02786826.2011.620041, 2012.

Mohr, C., Huffman, J. A., Cubison, M. J., Aiken, A. C., Docherty, K. S., Kimmel, J. R., Ulbrich, I. M., Hannigan, M., and Jimenez, J. L.: Characterization of primary organic aerosol emissions from meat cooking, trash burning, and motor vehicles with HighResolution Aerosol Mass Spectrometry and comparison with ambient and chamber observations, Environ. Sci. Technol., 43, 2443-2449, doi:10.1021/es8011518, 2009.

Ng, N. L., Canagaratna, M. R., Jimenez, J. L., Chhabra, P. S., Seinfeld, J. H., and Worsnop, D. R.: Changes in organic aerosol composition with aging inferred from aerosol mass spectra, Atmos. Chem. Phys., 11, 6465-6474, doi:10.5194/acp-11-64652011, 2011.

Paatero, P. and Tapper, U.: Positive matrix factorization: A nonnegative factor model with optimal utilization of error estimates of data values, Environmetrics, 5, 111-126, 1994.

Pope III, C. A., Ezzati, M., and Dockery, D. W.: Fine-Particulate Air Pollution and Life Expectancy in the United States, New Engl. J. Med., 360, 376-386, doi:10.1056/NEJMsa0805646, 2009.

Shao, M., Wang, B., Lu, S., Yuan, B., and Wang, M.: Effects of Beijing Olympics Control Measures on Reducing Reactive Hydrocarbon Species, Environ. Sci. Technol., 45, 514-519, doi:10.1021/es102357t, 2011.

Song, Y., Zhang, Y., Xie, S., Zeng, L., Zheng, M., Salmon, L. G., Shao, M., and Slanina, S.: Source apportionment of $\mathrm{PM}_{2.5}$ in Beijing by positive matrix factorization, Atmos. Environ., 40, 1526-1537, doi:10.1016/j.atmosenv.2005.10.039, 2006.

Sun, J., Zhang, Q., Canagaratna, M. R., Zhang, Y., Ng, N. L., Sun, Y., Jayne, J. T., Zhang, X., Zhang, X., and Worsnop, D. R.: Highly time- and size-resolved characterization of submicron aerosol particles in Beijing using an Aerodyne Aerosol Mass Spectrometer, Atmos. Environ., 44, 131-140, doi:10.1016/j.atmosenv.2009.03.020, 2010.

Sun, Y.-L., Zhang, Q., Schwab, J. J., Demerjian, K. L., Chen, W.N., Bae, M.-S., Hung, H.-M., Hogrefe, O., Frank, B., Rattigan, O. V., and Lin, Y.-C.: Characterization of the sources and processes of organic and inorganic aerosols in New York city with a high-resolution time-of-flight aerosol mass apectrometer, Atmos. Chem. Phys., 11, 1581-1602, doi:10.5194/acp-11-15812011, 2011.

Sun, Y. L., Wang, Z., Dong, H., Yang, T., Li, J., Pan, X., Chen, P., and Jayne, J. T.: Characterization of summer organic and inorganic aerosols in Beijing, China with an Aerosol Chemical Speciation Monitor, Atmos. Environ., 51, 250-259, doi:10.1016/j.atmosenv.2012.01.013, 2012a.

Sun, Y. L., Zhang, Q., Schwab, J. J., Chen, W.-N., Bae, M.-S., Hung, H.-M., Lin, Y.-C., Ng, N. L., Jayne, J., Massoli, P., Williams, L. R., and Demerjian, K. L.: Characterization of near-highway submicron aerosols in New York City with a high-resolution aerosol mass spectrometer, Atmos. Chem. Phys., 12, 2215-2227, doi:10.5194/acp-12-2215-2012, 2012 b.

Sun, Y. L., Wang, Z. F., Fu, P. Q., Yang, T., Jiang, Q., Dong, H. B., Li, J., and Jia, J. J.: Aerosol composition, sources and processes during wintertime in Beijing, China, Atmos. Chem. Phys., 13, 4577-4592, doi:10.5194/acp-13-4577-2013, 2013.
Sun, Y. L., Jiang, Q., Wang, Z., Fu, P., Li, J., Yang, T., and Yin, Y.: Investigation of the sources and evolution processes of severe haze pollution in Beijing in January 2013, J. Geophys. Res.Atmos., 119, 4380-4398, doi:10.1002/2014jd021641, 2014.

Sun, Y. L., Du, W., Wang, Q., Zhang, Q., Chen, C., Chen, Y., Chen, Z., Fu, P., Wang, Z., Gao, Z., and Worsnop, D. R.: Real-Time Characterization of Aerosol Particle Composition above the Urban Canopy in Beijing: Insights into the Interactions between the Atmospheric Boundary Layer and Aerosol Chemistry, Environ. Sci. Technol., 49, 11340-11347, doi:10.1021/acs.est.5b02373, 2015a.

Sun, Y. L., Wang, Z. F., Du, W., Zhang, Q., Wang, Q. Q., Fu, P. Q., Pan, X. L., Li, J., Jayne, J., and Worsnop, D. R.: Longterm real-time measurements of aerosol particle composition in Beijing, China: seasonal variations, meteorological effects, and source analysis, Atmos. Chem. Phys., 15, 10149-10165, doi:10.5194/acp-15-10149-2015, 2015 b.

Takegawa, N., Miyakawa, T., Watanabe, M., Kondo, Y., Miyazaki, Y., Han, S., Zhao, Y., van Pinxteren, D., Bruggemann, E., Gnauk, T., Herrmann, H., Xiao, R., Deng, Z., Hu, M., Zhu, T., and Zhang, Y.: Performance of an Aerodyne Aerosol Mass Spectrometer (AMS) during Intensive Campaigns in China in the Summer of 2006, Aerosol Sci. Tech., 43, 189-204, doi:10.1080/02786820802582251, 2009.

Turpin, B. J. and Lim, H. J.: Species contributions to PM2.5 mass concentrations: Revisiting common assumptions for estimating organic mass, Aerosol Sci. Tech., 35, 602-610, 10.1080/02786820152051454, 2001

Ulbrich, I. M., Canagaratna, M. R., Zhang, Q., Worsnop, D. R., and Jimenez, J. L.: Interpretation of organic components from Positive Matrix Factorization of aerosol mass spectrometric data, Atmos. Chem. Phys., 9, 2891-2918, doi:10.5194/acp-9-2891-2009, 2009.

Wang, H., Zhuang, Y., Wang, Y., Sun, Y., Yuan, H., Zhuang, G., and Hao, Z.: Long-term monitoring and source apportionment of $\mathrm{PM}_{2.5} / \mathrm{PM}_{10}$ in Beijing, China, J. Environ. Sci., 20, 1323-1327, 2008.

Wang, T., Nie, W., Gao, J., Xue, L. K., Gao, X. M., Wang, X. F., Qiu, J., Poon, C. N., Meinardi, S., Blake, D., Wang, S. L., Ding, A. J., Chai, F. H., Zhang, Q. Z., and Wang, W. X.: Air quality during the 2008 Beijing Olympics: secondary pollutants and regional impact, Atmos. Chem. Phys., 10, 7603-7615, doi:10.5194/acp10-7603-2010, 2010.

Wang, W., Primbs, T., Tao, S., and Simonich, S. L. M.: Atmospheric Particulate Matter Pollution during the 2008 Beijing Olympics, Environ. Sci. Technol., 43, 5314-5320, doi:10.1021/es9007504, 2009.

Wang, W., Jariyasopit, N., Schrlau, J., Jia, Y., Tao, S., Yu, T.-W., Dashwood, R. H., Zhang, W., Wang, X., and Simonich, S. L. M.: Concentration and Photochemistry of PAHs, NPAHs, and OPAHs and Toxicity of $\mathrm{PM}_{2.5}$ during the Beijing Olympic Games, Environ. Sci. Technol., 45, 6887-6895, doi:10.1021/es201443z, 2011.

Xu, J., Zhang, Q., Chen, M., Ge, X., Ren, J., and Qin, D.: Chemical composition, sources, and processes of urban aerosols during summertime in northwest China: insights from high-resolution aerosol mass spectrometry, Atmos. Chem. Phys., 14, 1259312611, doi:10.5194/acp-14-12593-2014, 2014. 
Zhang, H., Wang, S., Hao, J., Wan, L., Jiang, J., Zhang, M., Mestl, H. E. S., Alnes, L. W. H., Aunan, K., and Mellouki, A. W.: Chemical and size characterization of particles emitted from the burning of coal and wood in rural households in Guizhou, China, Atmos. Environ., 51, 94-99, doi:10.1016/j.atmosenv.2012.01.042, 2012.

Zhang, J., Wang, Y., Huang, X., Liu, Z., Ji, D., and Sun, Y.: Characterization of organic aerosols in Beijing using an aerodyne highresolution aerosol mass spectrometer, Adv. in Atmos. Sci., 32, 877-888, doi:10.1007/s00376-014-4153-9, 2015.

Zhang, J. K., Sun, Y., Liu, Z. R., Ji, D. S., Hu, B., Liu, Q., and Wang, Y. S.: Characterization of submicron aerosols during a month of serious pollution in Beijing, 2013, Atmos. Chem. Phys., 14, 2887-2903, doi:10.5194/acp-14-2887-2014, 2014.

Zhang, Q., Worsnop, D. R., Canagaratna, M. R., and Jimenez, J. L.: Hydrocarbon-like and oxygenated organic aerosols in Pittsburgh: insights into sources and processes of organic aerosols, Atmos. Chem. Phys., 5, 3289-3311, doi:10.5194/acp-5-32892005, 2005.

Zhang, Q., Jimenez, J. L., Worsnop, D. R., and Canagaratna, M.: A case study of urban particle acidity and its effect on secondary organic aerosol, Environ. Sci. Technol., 41, 3213-3219, 2007.

Zhang, Q. H., Zhang, J. P., and Xue, H. W.: The challenge of improving visibility in Beijing, Atmos. Chem. Phys., 10, 78217827, doi:10.5194/acp-10-7821-2010, 2010.
Zhang, R., Jing, J., Tao, J., Hsu, S.-C., Wang, G., Cao, J., Lee, C. S. L., Zhu, L., Chen, Z., Zhao, Y., and Shen, Z.: Chemical characterization and source apportionment of $\mathrm{PM}_{2.5}$ in Beijing: seasonal perspective, Atmos. Chem. Phys., 13, 7053-7074, doi:10.5194/acp-13-7053-2013, 2013.

Zhang, Y., Sun, J., Zhang, X., Shen, X., Wang, T., and Qin, M.: Seasonal characterization of components and size distributions for submicron aerosols in Beijing, Science China Earth Sciences, 56, 890-900, doi:10.1007/s11430-012-4515-z, 2012.

Zhang, Y. M., Zhang, X. Y., Sun, J. Y., Hu, G. Y., Shen, X. J., Wang, Y. Q., Wang, T. T., Wang, D. Z., and Zhao, Y.: Chemical composition and mass size distribution of $\mathrm{PM}_{1}$ at an elevated site in central east China, Atmos. Chem. Phys., 14, 12237-12249, doi:10.5194/acp-14-12237-2014, 2014.

Zheng, G. J., Duan, F. K., Su, H., Ma, Y. L., Cheng, Y., Zheng, B., Zhang, Q., Huang, T., Kimoto, T., Chang, D., Pöschl, U., Cheng, Y. F., and He, K. B.: Exploring the severe winter haze in Beijing: the impact of synoptic weather, regional transport and heterogeneous reactions, Atmos. Chem. Phys., 15, 2969-2983, doi:10.5194/acp-15-2969-2015, 2015.

Zheng, M., Salmon, L. G., Schauer, J. J., Zeng, L., Kiang, C. S., Zhang, Y., and Cass, G. R.: Seasonal trends in $\mathrm{PM}_{2.5}$ source contributions in Beijing, China, Atmos. Environ., 39, 3967-3976, doi:10.1016/j.atmosenv.2005.03.036, 2005. 